\title{
EGAPP supplementary evidence review: DNA testing strategies aimed at reducing morbidity and mortality from Lynch syndrome
}

\author{
Glenn E. Palomaki, BS $S^{1}$, Monica R. McClain, PhD ${ }^{I}$, Stephanie Melillo, MPH', Heather L. Hampel, $M S^{3}$, \\ and Stephen N. Thibodeau, PhD
}

\section{EXECUTIVE SUMMARY}

An original evidence review examined screening and diagnosis of hereditary nonpolyposis colorectal cancer (HNPCC) and the subsequent outcomes in a population of newly diagnosed cases of colorectal cancer (CRC). This supplementary evidence review focuses on five issues of further interest to the Evaluation of Genomic Applications in Practice and Prevention (EGAPP) Working Group (EWG), as summarized below.

1. Clarifying how to define the clinical disorder-Lynch syndrome. In this supplementary review, Lynch syndrome refers to individuals with a predisposition to CRC and certain other malignancies as a result of a germline mismatch repair (MMR) gene mutation-including those with an existing cancer and those who have not yet developed cancer. This definition allows planned analyses of clinical validity and utility to be more straightforward. Several recent editorials and publications recommend that the ambiguous term HNPCC be abandoned and that this clarified definition of Lynch syndrome should be used instead.

2. Removing family history from consideration as a preliminary test. A previous evidence review showed that screening performance of both the Amsterdam and the Bethesda criteria to identify individuals with Lynch syndrome were highly heterogeneous, possibly due to differences among the populations tested. In a general population, Amsterdam criteria are associated with relatively low sensitivity $(28-45 \%)$, but high specificity $(99 \%)$, whereas Bethesda criteria are associated with higher sensitivity (73-91\%), but at the cost of lower specificity $(82-77 \%)$. Neither provides the necessary high sensitivity/specificity in a reliable and consistent manner. There are also gaps in knowledge relating to the time required to

From the ${ }^{1}$ Department of Pathology and Laboratory Medicine, The Warren Alpert Medical School of Brown University, Women and Infants Hospital, Providence, Rhode Island; ${ }^{2}$ McKing Consulting Corporation, National Office of Public Health Genomics, Centers for Disease Control and Prevention, Atlanta, Georgia; ${ }^{3}$ Department of Internal Medicine, The Ohio State University, Arthur G. James Cancer Hospital and Richard J. Solove Research Institute, Columbus, Ohio; ${ }^{4}$ Department of Laboratory Medicine and Pathology, Mayo Clinic, Rochester, Minnesota.

Glenn E. Palomaki, BS, Division of Medical Screening, Women and Infants Hospital, 70 Elm Street, 2nd Floor, Providence, RI 02903. E-mail: gpalomaki@ipmms.org.

The findings and conclusions in this report are those of the authors and do not necessarily represent the official position of the Centers for Disease Control and Prevention.

Submitted for publication August 12, 2008.

Accepted for publication September 29, 2008

DOI: $10.1097 /$ GIM.0b013e31818fa2db collect family history, the consistency with which it is collected, and the accuracy of the information. These shortcomings have led us to remove family history from consideration as a preliminary test in individuals newly diagnosed with CRC. However, family history may still be an important component of CRC risk assessment in the general population.

3. Documenting the clinical validity of DNA-based preliminary tests. Because of rapid advances in knowledge and technology regarding molecular testing and Lynch syndrome, we generally limited this review to publications from 2003 and later. Although not formally studied, this is a likely reason why several of our estimates differ from those provided in an earlier evidence report. There was "Adequate" (a formal EWG term) evidence showing the sensitivity of microsatellite instability (MSI) testing to be about $89 \%$ (for mutations in the MMR genes MLH1 and MSH2), with a lower sensitivity of about $77 \%$ for $M S H 6$ mutations. Sensitivity was higher when three or more mononucleotide markers were included in the panel. Specificity was estimated to be $90.2 \%$, with an adequate level of evidence. There was also good evidence showing the sensitivity of immunohistochemical (IHC) testing to be $83 \%$, regardless of the underlying MMR gene involved. Specificity was more variable with a central estimate of $88.8 \%$, and an adequate level of evidence. Inadequate evidence was available to determine the distribution of mutations in the MMR genes, but the limited data suggest $32 \%$ will be in $M L H 1,38 \%$ in $M S H 2,14 \%$ in $M S H 6$, and $15 \%$ in $P M S 2$. Adequate evidence was available to estimate sensitivity (69\%) and specificity (point estimate of $100 \%$ ) for identifying Lynch syndrome using a specific mutation in the $B R A F$ gene among those with absent IHC staining for MLH1. An alternative to $B R A F$ mutation testing might be direct testing of $M L H 1$ methylation status, but this was not evaluated.

4. Benefits and harms to probands and relatives with Lynch syndrome. Between 2 and 12 first-degree relatives of probands (newly diagnosed CRC cases with Lynch syndrome, or index cases) can be contacted, based on resources and methodology. There was adequate evidence to document uptake of counseling among these firstdegree relatives who were contacted (52\%) and subsequently targeted for MMR gene mutation testing (95\%). Adequate evidence was found showing the risk of CRC by age 70 to be approximately $45 \%$ for men and $35 \%$ for women among relatives with Lynch syndrome. This is lower than earlier estimates, because of the more severe family histories included in earlier studies. Among relatives with Lynch syndrome, risks for endometrial cancer by 70 years of age are variable and range from as low as $31 \%$ to as high as $64 \%$. Some of the higher estimates, 
however, may be subject to family history bias. The U.S. Multisociety Task Force on Colorectal Cancer recommends colonoscopy every 1 or 2 years for first-degree relatives of individuals diagnosed with Lynch syndrome, and uptake among this group is about $80 \%$. The most serious adverse events associated with colonoscopy in the general population are bleeding (1.1/1000 individuals), perforation (3.3/1000), and death $(0.08 / 1000)$. Adequate evidence on the effectiveness of routine colonoscopy in relatives with Lynch syndrome is available from a controlled trial in Finland and from an observational cohort study in the Netherlands. Evidence, overall, was rated as Level IIb. By using an intention to treat analysis, the Finnish study reported that CRC incidence was reduced by $62 \%$, with no deaths among those undergoing surveillance, compared with nine in the control group. Other less direct studies suggest efficacy of periodic colonoscopy. Adequate evidence exists that $63 \%$ of women will adhere to endometrial cancer surveillance. Inadequate data are available to document that transvaginal ultrasound and endometrial biopsy can reduce the incidence of endometrial cancer. Hysterectomy and bilateral salpingo-oophorectomy are effective in reducing the risk for endometrial cancer, but uptake is low (19\%) and it has not been the standard of care to recommend this procedure.

5. Economic modeling of programmatic costs and costs per Lynch syndrome detected using four different testing strategies. Data from this supplementary review, along with other published information, were used to perform a cost-consequences analysis. Rather than looking at health outcomes, this type of analysis focuses on the direct consequences of testing. In this analysis, the costs per Lynch syndrome case detected were determined for four strategies that represent a wide range of possible testing/ diagnostic scenarios. The list of strategies is not intended to be exhaustive but to provide examples. It is assumed that the initial test in each of the four strategies described below would have $67 \%$ uptake so that detection rates for Lynch syndrome can be compared between strategies. Subsequent actions are modeled at rates found in the literature (e.g., uptake of counseling and testing among their relatives). Total program costs (preliminary testing, counseling, diagnostic testing, contacting relatives and targeted testing) are computed assuming a cohort of 150,000 newly diagnosed CRC cases with a $3 \%$ prevalence of Lynch syndrome.

a. Strategy 1. Individuals with newly diagnosed CRC (probands) would have MMR gene sequencing/deletion testing for MLH1, MSH2, and MSH6. This strategy will have the highest sensitivity for Lynch syndrome (about $85 \%$ or 2537 of the 3000 cases), and cost about $\$ 111,000(90 \% \mathrm{CI}, \$ 83,000-\$ 148,000)$ per proband with Lynch syndrome detected. If relatives of the proband are included in the analysis as well, the cost per adult with Lynch detected is reduced to about $\$ 72,000$ (90\% CI, \$49,000-\$101,000). Costs are reduced when relatives are included because they require only counseling and targeted testing for the family mutation. Total program costs for this strategy are about \$281 million.

b. Strategy 2. All probands would have quality MSI testing; those with high instability would have sequencing/deletion testing for the three MMR genes. This strategy will have a lower overall detection rate
( $73 \%$ or 2198 cases) because the MSI is not high in all individuals with Lynch syndrome. The cost per proband with Lynch syndrome detected is $\$ 47,000$ $(90 \% \mathrm{CI}, \$ 33,000-\$ 64,000)$. When relatives are included, the cost per case detected is reduced to $\$ 31,000(90 \%$ CI, $\$ 20,000-\$ 44,000)$. Total program costs are about $\$ 104$ million.

c. Strategy 3. All probands would have quality IHC testing; those with negative staining would have sequencing/deletion testing for the some of the three MMR genes. This strategy will have a slightly lower overall detection rate $(70 \%$ or 2105 cases), compared with Strategy 2, because IHC testing seems to be slightly less reliable when identifying probands with Lynch syndrome. The cost per Lynch syndrome proband detected is $\$ 21,000(90 \% \mathrm{CI}, \$ 14,000-\$ 29,000)$. When relatives are included, the cost per case detected is reduced to $\$ 14,000(90 \% \mathrm{CI}, \$ 9,000-\$ 20,000)$. The lower costs are because IHC testing provides information about which MMR gene(s) are likely to contain the mutation, thereby reducing testing costs for the probands. Total program costs are about $\$ 46$ million.

d. Strategy 4. Strategy 3 is modified so that probands with an IHC MLH1 negative stain are all tested for the specific $B R A F$ mutation. If that mutation is not found, the individual continues on for MMR gene(s) testing. If the mutation is found, no further testing (sequencing) is required as the chance of having Lynch syndrome is very low. The overall detection rate remains at about $70 \%$ (or 2097 cases), as the sensitivity of $B R A F$ mutation testing is close to $100 \%$. The cost per Lynch syndrome proband detected is $\$ 19,000(90 \% \mathrm{CI}, \$ 13,000-\$ 26,000)$. When relatives are included, the cost per case detected is reduced to $\$ 13,000(90 \% \mathrm{CI}, \$ 8,000-\$ 18,000)$. Total program costs are about $\$ 41$ million.

\section{IMPORTANT GAPS IN KNOWLEDGE}

- What is the clinical validity of sequentially applied screening tests (e.g., MSI, then IHC testing)?

- Is methylation testing useful as part of preliminary testing for Lynch syndrome?

- Additional information needs to be collected regarding the methods of identifying, approaching, educating, counseling, and testing relatives of probands with Lynch syndrome.

- Although randomized trials are unlikely, observational studies could provide additional information on whether systematic surveillance is effective in reducing Lynch syndrome-related morbidity and mortality for both CRC and other related cancers.

- Should the clinical care of CRC patients with Lynch syndrome be altered?

- Among females with Lynch syndrome, is endometrial cancer surveillance effective?

- A comprehensive cost-effectiveness analysis (CEA) should be performed as a way to help inform policymakers about which strategy(s) might be recommended.

\section{AIMS OF THIS SUPPLEMENTARY EVIDENCE REVIEW}

The aims of this supplementary evidence review are to reconsider aspects of the evidence regarding: (1) a clarified DNAbased definition of the clinical disorder; (2) performance characteristics of preliminary, laboratory-based tests, taking into 
account the technical laboratory issues and new markers; (3) an updated and expanded exploration of implications for other family members (psychosocial, as well as other benefits and harms); (4) the usefulness of considering family history as a preliminary test; and (5) an economic model for detecting Lynch syndrome that includes both probands and their first-degree relatives.

\section{BACKGROUND AND JUSTIFICATION}

Recently, an evidence report was released ${ }^{1}$ regarding the use of gene-based tests in the diagnosis and treatment of HNPCC. Its purpose was to inform the EGAPP Working Group (EWG) in making recommendations. Because these tests are rapidly evolving and the evidence report highlighted important gaps in knowledge, the EWG requested a supplementary report to provide updated information and an expanded evidence base upon which to build its recommendations. ${ }^{2}$ The updated information relies on the original evidence report as its basis, but adds to and extends those findings. This supplemental evidence was targeted at five specific areas after discussions with a Technical Evaluation Panel consisting of EWG members, Centers for Disease Control and Prevention (CDC) consultants and staff, and experts in the field of identifying Lynch syndrome $(\mathrm{H}$. Hampel) and laboratory testing for Lynch syndrome (S. Thibodeau). These five areas are summarized below and the first four are reviewed in detail in the remainder of this document.

\section{Clarifying how to define the clinical disorder-Lynch syndrome}

Defining Lynch syndrome (sometimes referred to as HNPCC) clinically, using family and personal history of cancer, is problematic. The original Amsterdam criteria were designed to identify a suitable group for further study of an inherited form of CRC; not to define a specific clinical disorder. Subsequent modifications to these criteria (e.g., Bethesda criteria) were interpreted as a more sensitive test for identifying inherited forms of CRC. However, such a group is heterogeneous, with some cancers caused by MMR gene mutations, others by inactivated MMR genes, and many others of unknown etiology. This has led to confusion in the literature. As a result, specifications for the primary, evidence-based review were difficult to shape, and it was determined that interpretation of data from that review would require supplementary information. The initial review helped the EWG realize that the clinical scenario needed to be refined. Consequently, the present document replaces a family history-based definition with a molecular definition that has recently been promulgated in the research community - individuals with an identifiable MMR gene mutation are defined as having Lynch syndrome, whether or not an existing CRC or other cancer is present.

\section{Removing family history from consideration as a preliminary test}

On the basis of the original evidence report, the EWG Technical Evaluation Panel members decided against using the family history as the initial screening test (e.g., Bethesda criteria) in this population. This was based on the difficulty and the costs of obtaining reliable family history, and the overall poor sensitivity and specificity.

\section{Documenting the clinical validity of DNA-based preliminary tests}

Significant new information is available in the literature, and we also reviewed whether any information in the original evi- dence review had become outdated. For example, older reports containing results for MMR gene testing used less sensitive technologies (e.g., denaturing gradient gel electrophoresis or single strand conformation polymorphism analyses) and did not check for large deletions. In addition, older tests for MSI relied on only a few repeated sequences, compared with more recent expanded testing panels that utilize three or more mononucleotide repeats. Given the rapid advances in both knowledge and technology, we also restricted literature searches to more recent dates and stratified results by technology to determine the impact of newer test panels. For example, we stratified the analysis of MSI testing by factors known to improve sensitivity (e.g., number of mononucleotide repeats).

\section{Benefits and harms to probands and relatives with Lynch syndrome}

The original evidence report (www.ahrq.gov/downloads/pub/ evidence/pdf/hnpcc/hnpcc.pdf) addressed anxiety and psychosocial issues, but did not address the medical harms related to screening and diagnosis in probands and relatives (e.g., additional colonoscopies) or the benefits in probands and relatives (e.g., avoidable CRC and endometrial cancer). In addition, neither uptake rates for subsequent screening nor effectiveness of screening tests were addressed. This type of information is necessary when balancing the benefits and harms of testing and diagnosis, and also to inform decision analysis/economic models. Data from the original evidence report were reanalyzed to determine whether more data from the breast cancer literature could be included to inform the review.

\section{Economic modeling of programmatic costs and costs per Lynch syndrome detected using four different testing strategies}

A more comprehensive set of models using updated information was requested in order that the EWG might create broad recommendations. For example, the model in the original evidence review did not consider the benefits that IHC testing provided in directing which MMR gene to sequence, nor did it include relatives of probands. Although it was not possible to perform a comprehensive CEA, it was possible to conduct a cost-consequences analysis to help inform recommendations.

\section{METHODS}

The EWG has explicit methods for both identifying published and gray data, and for ranking the quality of data sources ( 1 being the highest quality and 4 being the lowest) and quality of evidence (convincing being the highest, adequate and inadequate being the lowest). ${ }^{2}$ Criteria for both the quality of data sources and quality of evidence differ for analytic validity, clinical validity, and clinical utility. Specific details regarding the identification of data are contained within each section. In general, data identification was based on explicit search strategies for each question of interest, with occasional use of gray data, referral to the original evidence report, ${ }^{2}$ and in some instances, existing structured reviews. Although the analytic framework used for the original evidence review remains relevant, the present review does not address all aspects of the overarching question. For example, we did not systematically collect additional data regarding the analytic validity of preliminary DNA-based tests. An interpretation of the data are also provided for each question of interest that includes an assessment of quality of data and quality of evidence and identification of possible biases and gaps in knowledge. 


\section{RESULTS}

\section{Clarifying the definition of the disorder}

In this supplementary review, we will use the terminology and definitions as proposed by Jass ${ }^{3}$ and Lindor et al. ${ }^{4}$ Lynch syndrome will refer to an individual with a germline MMR gene mutation who has a predisposition to $\mathrm{CRC}$ and to certain other malignancies, or is diagnosed with one of these cancers. The term HNPCC will generally not be used except in direct reference to a publication. The following sections provide the rationale for this definition.

The term HNPCC is problematic and has multiple definitions (e.g., defined by family history, clinical, and/or pathologic features). In a 2005 editorial, Terdiman ${ }^{5}$ provides an example of how the terms Lynch syndrome and HNPCC have multiple and overlapping definitions which can cause confusion.

HNPCC, also called Lynch syndrome after Henry $\mathrm{T}$. Lynch, MD, a pioneer in the field, is an autosomal dominant hereditary cancer syndrome which accounts for upwards of $3 \%$ of all $\mathrm{CRC}$, and is associated with an increased risk of endometrial, ovarian, and other extracolonic cancers .... The syndrome originally was defined in clinical terms by the stringent Amsterdam criteria, although over time, more relaxed clinical definitions have been suggested, culminating in the recently published revised Bethesda guidelines. Many cases of clinically defined Lynch syndrome are caused by a germline mutation in one of a set of genes responsible for DNA mismatch repair.

A solution to the confusion of terms is best summarized by Jass. ${ }^{3}$

The term HNPCC is a poor descriptor of the syndrome described by Lynch. Over the last decade, the term has been applied to heterogeneous groups of families meeting limited clinical criteria, for example, the Amsterdam criteria. It is now apparent that not all Amsterdam criteria-positive families have the Lynch syndrome. The term HNPCC has also been applied to clinical scenarios in which CRCs with DNA microsatellite instability are diagnosed but in which there is no vertical transmission of an altered DNA mismatch repair gene. A term that has multiple, mutually incompatible meanings is highly problematic, particularly when it may influence the management of an individual family. The Lynch syndrome is best understood as a hereditary predisposition to malignancy that is explained by a germline mutation in a DNA MMR gene. The diagnosis does not depend in an absolute sense on any particular family pedigree structure or age of onset of malignancy.

These definitions were extended by Lindor et al. ${ }^{4}$ who suggest using the term Familial CRC Type $\mathrm{X}$ to describe individuals in families satisfying stringent family history criteria (e.g., Amsterdam) who have no evidence of a MMR gene mutation.

The use of HNPCC as a label needs to be refined or made obsolete. The term HNPCC encompasses considerable heterogeneity and has come to mean different entities to different people. We prefer the term "Lynch syndrome" or "HNPCC Lynch syndrome" to specify those individuals or families with germline mutations in the DNA MMR genes .... It may be reasonable to introduce a term for families similar to our group B families, who have a clustering of CRC but in whose tumors no DNA MMR gene defect is evident. We suggest the term "familial colorectal cancer type X." This term does not define these groups as having hereditary CRC (which usually implies single-gene etiology), and it acknowledges our lack of understanding of the etiology (thus the "X") . . . Regardless of what term is eventually adopted, it is essential that the term HNPCC not be used without clearly defining it, to acknowledge that families with Lynch syndrome (hereditary DNA MMR deficiency) and those with familial colorectal cancer type $\mathrm{X}$ are not equivalent entities.

This is not to say that all experts in the field are consistently using this terminology at this point in time. In a 2007 article by Lynch et al., ${ }^{6}$ the terms HNPCC and Lynch syndrome are still, apparently, used interchangeably.

Before molecular genetic diagnosis came of age in the 1990 s, a comprehensive family history was the only basis on which familial risk of CRC could be estimated. In the case of HNPCC, also known as Lynch syndrome, the historic perspective offered by Warthin in 1895 has not changed appreciably.

\section{Performance of DNA-based tests in the context of a molecularly defined disorder}

\section{What is the clinical sensitivity of MSI testing to identify individuals with Lynch syndrome?}

The optimal study design for this purpose would be population based, enrolling a large group of individuals consecutively diagnosed with CRC. Initially, MMR gene mutation testing, accounting for as many major mutations as possible, would be performed on all of these cases. MSI testing would then be performed on samples from all cases with a mutation. Testing (both for MSI and MMR mutations) would utilize the technology currently in use. We restricted the search to articles published in 2003 and later, to help ensure that retrieved studies utilized current testing technologies. By that time, testing laboratories often would have (1) incorporated the basic National Cancer Institute (NCI) panel $^{7}$ for MSI testing; (2) included additional mononucleotide markers to improve performance ${ }^{8,9}$; (3) routinely tested for mutations in MSH6 and, possibly, PMS2; and (4) routinely tested for large deletions in MMR genes using multiplex ligation-dependent probe amplification. We searched PubMed from 2003 through June 2007, using the MeSH terms "(Colorectal Neoplasms or Hereditary Nonpolyposis) and (MSI or microsatellite instability)," restricted to humans and the English language. Overall, 212 articles were identified. Two of us (G.E.P. and S.M.) reviewed the 212 abstracts and agreed that 28 full articles should be reviewed for appropriateness. Of these 28 articles, 11 met the following inclusion criteria. ${ }^{10-20}$ (1) MMR gene mutations were identified without knowledge of MSI status (in at least an identifiable subset of the data); (2) MSI testing was attempted on all patients with Lynch syndrome; (3) the MSI testing methodology was described in sufficient detail to rate test quality; and (4) the MMR gene with the mutation was identifiable.

The analysis was restricted to individuals with CRC (a few excluded studies included only patients with endometrial or breast cancer). In some studies, a few individuals had multiple CRC tumors tested. We chose the earliest sample with complete test results (i.e., MSI and IHC), to best simulate what might 
happen as part of routine evaluation in the future. In some studies, there were a few instances of multiple family members being tested. We chose to use the family member with the youngest age of onset for a CRC who had complete test results. Assessment of MSI test quality was defined before reviewing the articles and consisted of four questions: (1) did the authors discuss whether microdissection was performed, and whether it was manual or via laser; (2) how many mononucleotide markers were included in the panel; (3) were both tumor and normal tissue used in determining MSI status; and (4) was a minimum proportion of tumor cells required (e.g., $30 \%$ or higher).

Of the 11 studies examined, ${ }^{10-20}$ only one was close to being population based, but it was restricted to CRC diagnosed under age $55 .{ }^{10}$ Because of the relatively low prevalence of Lynch syndrome (about 2-4\%), comprehensive MMR gene testing among all CRC patients in the general population would be expensive. It is for this reason that the 11 studies used various definitions of high-risk populations, such as the Amsterdam or the Bethesda criteria, some other family history-based definition, or early age of onset for the proband (e.g., $<55$ years of age). If a study included some patients in whom MMR gene mutations were sought because of a positive MSI test result, that study was used only if an identifiable subset of the study population was identified with nonbiased criteria (e.g., family history). ${ }^{19}$ The studies were performed in North America, ${ }^{13}$ Europe, ${ }^{10-12,15-18,20}$ Asia, ${ }^{14}$ and Australia. ${ }^{19}$ The smallest included five individuals/families ${ }^{14}$ with Lynch syndrome; the largest included 26 patients $^{10}$ (average 15); MSI results were available for a total of 150 Lynch syndrome patients.

Table 1 shows the estimated clinical sensitivities for MSI testing (positive defined as MSI-high, negative as MSI-low or MSI-stable) to identify MMR mutations. Eleven studies reported MSI results for 81 Lynch syndrome patients with mutations in $M L H 1$. Combining the study results using a random effects model, the sensitivity of MSI testing was $85 \%(95 \% \mathrm{CI}$, 75-92\%). The bolded rows indicate summary information for a particular MMR gene. Non-bolded clinical sensitivity estimates (last column) indicate results stratified by MSI test quality. The same studies identified 59 Lynch syndrome patients with a MSH2 mutation and found the sensitivity of MSI testing to be $85 \%$ (95\% CI, 73-93\%). Five studies identified 67 patients with MSH6 mutations and found the sensitivity of MSI testing to be $69 \%(95 \%$ CI, 46-85\%). When assessing test quality, we found that all 11 studies reported using both tumor and normal tissue to assign MSI status. None of the studies explicitly reported laser microdissection, which has been reported to be the optimal method for sample preparation. ${ }^{21}$ In addition, none of the studies reported a minimum proportion of tumor cells. Roughly half of the studies, however, relied solely on the 1998 NCI recommended panel ${ }^{7}$ that includes only two mononucleotide markers (labeled as a 2 under the "MSI test quality" column), whereas the remaining studies utilized three or more mononucleotide markers (labeled as a $3+$ under the MSI test quality column). When the results are stratified by this quality measure (last column in Table 1), the clinical sensitivities of studies using three or more mononucleotide markers are consistently higher ( $91 \%$ vs. $80 \%$ for MLH1, $87 \%$ vs. $84 \%$ for $M S H 2$, and $77 \%$ vs. $55 \%$ for $M S H 6)$. This provides evidence supporting several methodological studies $^{8,9,21,22}$ and a more recent NCI report ${ }^{23}$ suggested that additional mononucleotide markers (up to five) be included in an MSI panel for clinical testing. Only one study reported a Lynch syndrome patient with a PMS2 mutation ${ }^{19}$ and found an MSI-stable result, but only 4 of the 10 MSI test markers provided interpretable results.
A high proportion of Lynch syndrome patients with mutations in the $M L H 1$ and $M S H 2$ genes can be identified via MSI-high test results. The best estimate of sensitivity with the use of two mononucleotide markers in the NCI recommended panel is $80-84 \%$, but with the use of at least three mononucleotide markers, the sensitivity can be increased to $87-91 \%$. Clinical sensitivity seems to be lower for MSH6, with the corresponding estimates of $55 \%$ and $77 \%$ depending on the number of mononucleotide markers used. The greater discrepancy between these two estimates is likely due to a known reduction in the sensitivity of dinucleotide microsatellites to MSH6 mutations. ${ }^{24}$

\section{What are the study limitations for the clinical sensitivity for MSI testing?}

All of the studies would be ranked as quality Level 2 or 3; the lower ranking because the settings are all high-risk population (e.g., families who satisfy Amsterdam criteria) rather than population based. This may lead to an overestimate of sensitivity, if MSI test results were related to penetrance. However, this does not seem to be the case. When the population-based results for those younger than 55 years $(80 \%$ for $M L H 1$ and $82 \%$ for MSH2) are compared with the other four studies that were based on strong family histories regardless of age ( $82 \%$ for $M L H 1$ and $88 \%$ for $M S H 2$ ), the results are remarkably similar. The quality of evidence is considered adequate for estimating MSI sensitivity for $M L H 1, M S H 2$, and MSH6. Few data are available from individuals other than non-Hispanic whites. The one study in Asians included only five patients with Lynch syndrome, ${ }^{14}$ and it found an average MSI sensitivity of $80 \%$. No estimate of clinical sensitivity for $P M S 2$ was made due to the low number of reported results. In subsequent modeling, the sensitivity of MSI testing for $P M S 2$ will be considered equivalent to that for MSH6-lower than that found for MLH1 and MSH2.

\section{How can clinical sensitivity of MSI testing be improved?}

It is unlikely that clinical sensitivity would ever reach $100 \%$, even if the laboratory test were to be improved and preanalytic/ postanalytic errors eliminated. There is room for improvement, however, as it is likely that none of the studies under review used the most sophisticated MSI test now possible for identifying CRC patients with Lynch syndrome. Methodological studies have shown the importance of laser microdissection, ${ }^{21,25}$ the proportion of tumor tissue tested, and the number of cells tested. ${ }^{25,26}$ Other studies have provided ways to improve testing of poor quality samples. ${ }^{26,27}$ If these techniques had been included in studies under review, even higher clinical sensitivities might have been obtained. Several researchers have examined the possible reasons for an MSI-low or MSI-stable in a confirmed Lynch syndrome patient. ${ }^{21,22,25,26}$ In the majority of instances, a methodological reason for the initial false-negative result was identified. One study found that, for certain large deletions in MSH2, one of the mononucleotide markers (BAT26) appeared MSI-stable. It was inferred that this was due to the complete absence of the target BAT26 sequences in the tumor sample resulting in amplification of contaminated normal DNA. ${ }^{28}$

\section{What might the clinical sensitivity be for laboratories offering MSI testing in the United States and Europe?}

External proficiency testing results from the United States and elsewhere indicated that current practice for MSI testing is not optimal in most laboratories. Based on this, it is likely that clinical sensitivity in routine practice for mutations in $\mathrm{MLH1}$ and $M S H 2$ will generally be toward the lower end of the range 
Table 1 Clinical sensitivity (detection rate) of microsatellite instability (MSI) testing to identify Lynch syndrome ${ }^{a}$

\begin{tabular}{|c|c|c|c|c|c|c|c|c|}
\hline \multirow[b]{2}{*}{ Reference } & \multirow{2}{*}{$\begin{array}{l}\text { MMR } \\
\text { gene }\end{array}$} & \multirow{2}{*}{$\begin{array}{c}\text { Total } \\
\text { number }\end{array}$} & \multicolumn{3}{|c|}{ Total with } & \multirow{2}{*}{$\begin{array}{c}\text { Study's } \\
\text { MSI-H (\%) }\end{array}$} & \multirow{2}{*}{$\begin{array}{l}\text { MSI } \\
\text { test quality }\end{array}$} & \multirow{2}{*}{$\begin{array}{c}\text { Clinical } \\
\text { sensitivity (\%) }\end{array}$} \\
\hline & & & MSI-H & MSI-L & MSI-S & & & \\
\hline Barnetson et al. ${ }^{10}$ & $M L H 1$ & 10 & 8 & 2 & 0 & 80 & 2 & \\
\hline Hoedema et al. ${ }^{13}$ & $M L H 1$ & 4 & 2 & nd & 2 & 50 & 2 & \\
\hline Lee et al. ${ }^{14}$ & $M L H 1$ & 4 & 3 & 0 & 1 & 75 & 2 & \\
\hline Luo et al. ${ }^{122}$ & $M L H 1$ & 2 & 2 & 0 & 0 & 100 & 2 & \\
\hline Niessen et al. ${ }^{15}$ & $M L H 1$ & 8 & 8 & 0 & 0 & 100 & 2 & \\
\hline Overbeek et al. ${ }^{123}$ & $M L H 1$ & 3 & 3 & 0 & 0 & 100 & 2 & \\
\hline Wolf et al ${ }^{16}$ & $M L H 1$ & 9 & 8 & 0 & $1^{c}$ & 89 & 2 & $80(54-90)$ \\
\hline Hendriks et al. ${ }^{11}$ & $M L H 1$ & 12 & 11 & 0 & 1 & 92 & $3+$ & \\
\hline Plevova et al. et al. ${ }^{18}$ & $M L H 1$ & 18 & 16 & 1 & 1 & 89 & $3+$ & \\
\hline Southey et al. ${ }^{19}$ & $M L H 1$ & 5 & 5 & 0 & 0 & 100 & $3+$ & \\
\hline Spaepen et al. ${ }^{20}$ & $M L H 1$ & 6 & 6 & 0 & 0 & 100 & $3+$ & $91(77-96)$ \\
\hline All & MLH1 & 81 & 72 & 3 & 6 & & Any & $85(75-92)$ \\
\hline Barnetson et al. ${ }^{10}$ & MSH2 & 11 & 9 & 2 & 0 & 82 & 2 & \\
\hline Hoedema et al. ${ }^{13}$ & MSH2 & 2 & 1 & nd & 1 & 50 & 2 & \\
\hline Lee et al. ${ }^{14}$ & $\mathrm{MSH} 2$ & 1 & 1 & 0 & 0 & 100 & 2 & \\
\hline Luo et al. ${ }^{122}$ & MSH2 & 1 & 1 & 0 & 0 & 0 & 2 & \\
\hline Niessen et al. ${ }^{15}$ & MSH2 & 6 & 6 & 0 & 0 & 100 & 2 & \\
\hline Overbeek et al. & $\mathrm{MSH} 2$ & 10 & 9 & 0 & 1 & 90 & 2 & \\
\hline Wolf et al. ${ }^{16}$ & $\mathrm{MSH} 2$ & 8 & $7^{d}$ & 0 & $1^{c}$ & 87 & 2 & $84(68-93)$ \\
\hline Hendriks et al. ${ }^{11}$ & $\mathrm{MSH} 2$ & 5 & 5 & 0 & 0 & 100 & $3+$ & \\
\hline Plevova et al. ${ }^{18}$ & $\mathrm{MSH} 2$ & 4 & 3 & 0 & 1 & 75 & $3+$ & \\
\hline Southey et al. ${ }^{19}$ & MSH2 & 2 & 2 & 0 & 0 & 100 & $3+$ & \\
\hline Spaepen et al. ${ }^{20}$ & MSH2 & 9 & 9 & 0 & 0 & 100 & $3+$ & $87(63-96)$ \\
\hline All & MSH2 & 59 & 53 & 2 & 4 & & Any & $85(73-93)$ \\
\hline Barnetson et al. ${ }^{10}$ & MSH6 & 5 & 1 & 2 & 2 & 20 & 2 & \\
\hline Niessen et al. ${ }^{15}$ & MSH6 & 7 & 4 & 3 & 0 & 57 & 2 & \\
\hline Overbeek et al. ${ }^{123}$ & MSH6 & 5 & 6 & 0 & 1 & 83 & 2 & $55(21-85)$ \\
\hline Hendriks et al. ${ }^{12}$ & MSH6 & 21 & 18 & $3^{e}$ & 0 & 86 & $3+$ & \\
\hline Plaschke et al. ${ }^{17}$ & MSH6 & 27 & 22 & 4 & 1 & 81 & $3+$ & \\
\hline Southey et al. ${ }^{19}$ & MSH6 & 2 & 0 & 2 & 0 & 0 & $3+$ & 77 (50-92) \\
\hline All & MSH6 & 67 & 51 & 14 & 4 & & Any & $69(46-85)$ \\
\hline
\end{tabular}

Hoedema et al. ${ }^{13}$ collapsed the MSI-L results into the MSI-S category.

${ }^{a}$ Lynch syndrome defined as an individual with an identified mutation in a mismatch repair gene.

${ }^{b}$ Based on four quality measures: (1) sample microdissection discussed, (2) three or more mononucleotide markers, (3) use of normal and tumor tissue in scoring, and (4) minimum proportion of tumor cells in preparation. Higher numbers indicate higher compliance with quality measures.

${ }^{c}$ In Wolf et al. ${ }^{16}$ this family was assigned both an MSI-H and MSI-S; here they are counted as MSI-S.

${ }^{d}$ In Wolf et al. ${ }^{16}$ one of these families was assigned both an MSH-H and MSI-S; here they are counted as MSI-H.

${ }^{e}$ In Hendriks et al. ${ }^{12}$ collapsed the MSI-L results into the MSI-S category.

nd, not done.

found earlier (about 84-90\%). Corresponding clinical sensitivity for MSH6 will be even lower.

- A 2006 study reported the results from a questionnaire completed by the five clinical laboratories in the United
Kingdom offering MSI testing as part of CRC follow-up. ${ }^{29}$ The survey showed wide variation in the microsatellites selected for inclusion in the panel. Little information is available regarding tissue preparation. A survey of six laboratories in the United States in $2006^{30}$ identified sev- 
eral key components aimed at assuring reliable MSI testing, including (1) optimizing the PCR products, (2) utilizing three or more mononucleotide markers, (3) standardizing how to determine an "equivocal" result, and (4) performing duplicate readings to reduce human errors.

- The College of American Pathologists has offered proficiency testing for MSI testing since 2003 through the Molecular Pathology Committee. ${ }^{31}$ Twice yearly, one unstained paraffin section is sent to participants, along with a case description. Laboratories are asked to perform MSI testing, answer accompanying technical questions about their methodology, and provide a test interpretation. Roughly 50 laboratories (mainly in North America) participate in the survey, which found important differences in test methodology, including the number and type of markers included (e.g., mononucleotide, dinucleotide) and protocols for sample preparation (microdissection and proportion of tumor cells required for reliable testing). Data suggest that at least some of the identified errors can be attributed to test methodology. Overall, there seems to be room for improvement in the technical aspects of MSI testing in clinical laboratories.

\section{What is the clinical specificity of MSI testing when identifying Lynch syndrome?}

In this review, the false-positive rate $(1-$ specificity $)$ is calculated initially, and then converted into the clinical specificity. The false-positive rate can be defined as the proportion of tested individuals in the population of interest (consecutive patients with CRC) without the disorder of interest (Lynch syndrome) that has MSI-high test results. By definition, Lynch syndrome is CRC caused by a MMR gene mutation. Most MSI-high test results that are not associated with a germline MMR gene mutation are explained by a nonfunctional MMR gene (MMR gene proteins are nonfunctional because of a somatic event). The most common cause is somatic methylation of the promoter region for $M L H 1$, often referred to as sporadic MSI CRC. ${ }^{32}$ Lynch syndrome and sporadic MSI CRC have morphologic features in common (lymphocytic infiltration, mucin secretion, and poor differentiation) that clearly separate them from other sporadic CRC. Lynch syndrome, however, is more often associated with a positive family history and early age of onset, whereas MSI CRCs are more common in women and occur at later ages. Thus, the "false positive" MSI-high test results indicate that the cancer is likely caused by failure of the
MMR gene, by a different mechanism (i.e., nonheritable $M L H 1$ promoter methylation).

\section{What study designs are optimal to define the clinical specificity for MSI testing?}

For the setting of population-based testing of newly diagnosed CRC cases, the optimal study design would be a consecutive series of individuals, all of whose tumors are tested for both MSI and MMR gene mutations (preferably for both point mutations and large deletions in MLH1, MSH2, MSH6, and PMS2). Among those individuals without an identified mutation (non-Lynch syndrome), the proportion with an MSI-high test result would be the false-positive rate from which the specificity can be computed. Studies that enroll only Amsterdam criteriapositive patients, or limit enrollees by age of onset (e.g., $<40$ years) would not be appropriate. However, studies that do not identify all cases of Lynch syndrome (e.g., only identify mutations among MSI-high patients) may also be acceptable, as the incidence of sporadic MSI CRC is high when compared to the incidence of Lynch syndrome.

\section{Clinical specificity for MSI testing in population-based cohorts of CRCs}

Although we would have preferred to restrict studies included in this section to the time period of 2003 and later (so that MSI testing methodologies would be similar to those used to define clinical sensitivity), the limited number of available studies did not allow for this. Six studies provided sufficient information to compute the clinical specificity of MSI testing. The consensus estimate for the clinical specificity of MSI testing is $90.2 \%$ (95\% CI, 87.7-92.7\%), using a random effects model. When expressed as a false-positive rate, the estimates are $9.8 \%(95 \% \mathrm{CI}, 7.3-13.0 \%)$. These results are heterogeneous, and this is only partially explained by study design or MSI test composition (numbers and types of microsatellites tested).

In all studies, we used only MSI-high results as being positive and included both MSI-low and MSI-stable as negative. Table 2 summarizes the results of MSI testing from studies that reported on consecutive newly diagnosed CRC from a general population. One of the studies restricted enrollment to patients under age 55. ${ }^{10}$ Another reported being conducted at a referral center, but enrolled consecutive newly diagnosed cases. ${ }^{33}$ Overall, the studies tested 3842 patients (after those with known

Table 2 Clinical specificity of microsatellite instability (MSI) testing to identify Lynch syndrome (LS)

\begin{tabular}{|c|c|c|c|c|c|c|c|c|}
\hline \multirow[b]{2}{*}{ Reference } & \multirow[b]{2}{*}{ Location } & \multirow{2}{*}{$\begin{array}{l}\text { CRC patients } \\
\text { enrolled }\end{array}$} & \multirow{2}{*}{$\begin{array}{l}\text { Average } \\
\text { age }\end{array}$} & \multirow{2}{*}{$\begin{array}{c}\text { Incidence of } \\
\text { LS (\%) }\end{array}$} & \multicolumn{2}{|c|}{ No. controls } & \multirow[b]{2}{*}{ Clinical specificity $(\%)$} & \multirow[b]{2}{*}{ FPR $(\%)$} \\
\hline & & & & & Tested & Positive & & \\
\hline Barnetson et al. ${ }^{10}$ & Scotland & $870(69)$ & 48 & 4.4 & 322 & 24 & 92.5 & 7.5 \\
\hline Pinol et al. ${ }^{34}$ & Spain & $1222(62)$ & 70 & 0.9 & 1211 & 73 & 94.0 & 6.0 \\
\hline Hampel et al. ${ }^{37}$ & USA & $1066(88)$ & 63 & 2.2 & 1043 & 114 & 89.1 & 10.9 \\
\hline Cunningham et al. ${ }^{33}$ & USA & $257(50)$ & 69 & 2.7 & 250 & 44 & 82.4 & 17.6 \\
\hline Salovaara et al. ${ }^{35}$ & Finland & $535(90)$ & 67 & 3.4 & 517 & 48 & 90.7 & 9.3 \\
\hline Aaltonen et al. ${ }^{38}$ & Finland & $509(67)$ & 68 & 2.0 & 499 & 53 & 89.4 & 10.6 \\
\hline All & & 4459 & & & 3842 & 356 & $90.2^{a}(87.0-92.7)$ & $9.8^{a}(7.3-13.0)$ \\
\hline
\end{tabular}

${ }^{a}$ Estimated using a random effects model.

FPR, false-positive rate (100 - clinical specificity). 
mutations were removed); 356 MSI-high test results were identified in that group. Formal meta-analysis shows significant heterogeneity $(Q=40, P<0.001)$, because one U.S. study reported a false-positive rate of $17.6 \%$, whereas the remaining studies averaged about $9 \%$

As a way of assessing heterogeneity, we examined several possible biases. Two studies ${ }^{34,35}$ used only BAT26 (a mononucleotide marker) to define MSI status. Such a test is likely to have a higher specificity (lower false-positive rate) than a more complete panel. Consistent with this expectation, both of these studies have higher specificities (lower false-positive rates) than the consensus figure. There is no obvious reason why specificity was so low in one study $(82.4 \%) .{ }^{32}$ Given that this was a referral center, some patients might have been enrolled after having already undergone MSI testing at an outlying institution. We kept this study in the analysis, as it offsets the studies biased toward high specificity and results in assigning a broad confidence interval.

Individual study quality for the six studies that estimated MSI specificity are all rated at quality Level 2 or 3 . The quality of evidence is at least adequate because of the observed heterogeneity in the results. However, there are reasonable explanations (provided above) for most high and low estimates, and it might also be reasonable to assign a convincing quality of evidence.

\section{Clinical sensitivity of IHC testing to identify individuals with Lynch syndrome}

The optimal study design for determining the clinical sensitivity of IHC testing is similar to that for MSI testing. Even though less obvious improvements may have occurred in IHC testing as compared with MSI testing, we restricted publications to 2003 and later for consistency and to avoid any temporal differences. The inclusion criteria were (1) MMR gene mutations were identified without knowledge of IHC status (in at least an identifiable subset of the data); (2) IHC testing was attempted on all patients with Lynch syndrome; and (3) the MMR gene with the mutation was identifiable. We searched the English language literature from January 2003 through June 2007, using the MeSH terms "(Colorectal Neoplasms or Hereditary Nonpolyposis) and (IHC or immunohistochemical)," restricted to humans. Overall, four articles were identified. Two of us (G.E.P. and S.M.) reviewed the abstracts and agreed that all four full articles should be reviewed. Although it was determined that none of these four satisfied the inclusion criteria, we identified nine additional articles that did. These were identified through reference lists from the four retrieved articles, through inclusion in the MSI review, or through inclusion in the original evidence report. In the few instances where articles reported on multiple cancers in the same individual or for multiple members of the same family, rules similar to those described for determining MSI sensitivity were used. All nine studies used various definitions of high-risk populations, such as the Amsterdam or the Bethesda criteria, some other family history-based definition, or early age of onset for the proband (e.g., $<55$ years). The studies were performed in North America, ${ }^{13}$ Europe, ${ }^{10-12,15,17,18,20}$ Asia, ${ }^{14}$ and Australia. ${ }^{19}$ The smallest included three individuals/families ${ }^{14}$ with Lynch syndrome; the largest included 31 patients $^{10}$ (average 16); IHC results were available for 149 Lynch syndrome patients.

Table 3 shows the estimated clinical sensitivities for IHC testing to identify MMR mutations (a correct test result is defined as a combination of IHC test results that indicate that sequencing is warranted). For example, the result is counted as correct when MLH1 protein is reported not to be present in the nucleus of tumor tissue (usually reported as negative or absent for protein in the tumor of a patient with a known MLH1 mutation). We performed the analysis of IHC sensitivity twice. In one analysis, we included samples in which failures occurred and considered these to be false negatives. In a second, less strict analysis, these failures were removed and one sample (reported to have reduced, but not negative expression of MLH1 protein) was reclassified as negative. Under the second set of columns labeled "Less Strict Interpretation," Table 3 shows that seven studies reported IHC results for 58 Lynch syndrome patients with mutations in $\mathrm{MLHI}$ and found the sensitivity of IHC testing to be $83 \%(95 \%$ CI, 65-93\%). The same seven studies identified 40 Lynch syndrome patients with an MSH2 mutation and found the sensitivity of IHC testing to also be $83 \%$ (95\% CI, 65-92\%). Finally, five studies identified 33 patients with MSH6 mutations and found the sensitivity of IHC testing again to be $83 \%(95 \% \mathrm{CI}, 66-93 \%)$. As expected, the "strict interpretation" results are consistently lower by three to nine percentage points. One study ${ }^{36}$ reported IHC test results for mutations in PMS2 (7 of 7 were absent protein staining). These results were not included in the table.

All of the studies providing IHC sensitivity estimates are of quality level 2 or 3 because of the high-risk population studied. The quality of evidence for sensitivity for $M L H 1, M S H 2$, and MSH6 mutations is adequate. Few data are available to estimate sensitivity for $P M S 2$, but performance is likely to be similar to that found for the other MMR genes.

\section{Clinical specificity of IHC testing for Lynch syndrome in population-based cohorts of CRCS}

Table 4 shows the consensus estimate for the clinical specificity of IHC testing, based on three studies. The overall estimate of specificity is $88.8 \%$ (95\% CI, 67.6-94.8\%), using a random effects model. When expressed as a false-positive rate, the estimate is $11.2 \%(95 \% \mathrm{CI}, 5.2-22.4 \%)$. Analysis shows the results to be heterogeneous $(Q=49, P<0.001)$, only part of which might be explained by study design or IHC test composition. All three studies are graded Level 2 or 3 . Given that the heterogeneity between studies cannot be fully explained, the level of evidence is considered adequate.

\section{Distribution of MMR gene mutations among Lynch syndrome patients in the general population}

Few, if any, studies have performed comprehensive identification of all Lynch syndrome patients from a general population of newly diagnosed CRC patients. However, several of the studies included for the analysis of clinical specificity identified a high proportion of Lynch syndrome patients and an analysis of their data can be instructive, even though it may not be definitive. Table 5 shows the number of mutations identified in each of the four major MMR genes from the six studies previously examined (Tables 2 and 4). Only one study attempted to identify mutations in all four genes. ${ }^{37}$ Since that study was published, further PMS2 testing has identified three additional deleterious PMS2 mutations (Hampel, unpublished study). Another study sequenced three genes (omitting $P M S 2$ ) and the remaining four studies sequenced only $M L H 1$ and $M S H 2$. The two studies from Finland ${ }^{35,38}$ report a very different ratio between $M L H 1$ and MSH2 mutations identified (26:3), compared with the remaining studies (28:39). This is a result of a founder effect, which will not be representative of rates in other populations. The four analyzed studies are from Scotland, ${ }^{10}$ Spain, ${ }^{34}$ and the United States. ${ }^{33,37}$ We referenced the ratio of mutations in $M L H 1$, MSH6, and PMS2 to the most common MMR gene to have mutations-MSH2. After weighting by the number of observa- 
Table 3 Clinical sensitivity (detection rate) of immunohistochemical (IHC) testing to identify Lynch syndrome ${ }^{a}$

\begin{tabular}{|c|c|c|c|c|c|c|c|}
\hline \multirow[b]{2}{*}{ Reference } & \multirow[b]{2}{*}{ Gene } & \multicolumn{3}{|c|}{ "Strict" interpretation ${ }^{a}$} & \multicolumn{3}{|c|}{ "Less strict" interpretation ${ }^{b}$} \\
\hline & & $\begin{array}{c}\text { Number } \\
\text { correct }\end{array}$ & $\begin{array}{l}\text { IHC } \\
\text { tested }\end{array}$ & $\begin{array}{c}\text { Clinical } \\
\text { sensitivity }(\%)\end{array}$ & $\begin{array}{c}\text { Number } \\
\text { correct }\end{array}$ & $\begin{array}{l}\text { IHC } \\
\text { tested }\end{array}$ & $\begin{array}{c}\text { Clinical } \\
\text { sensitivity }(\%)\end{array}$ \\
\hline Barnetson et al..$^{10}$ & $M L H 1$ & 9 & 10 & 90 & 9 & 9 & 100 \\
\hline Hendriks et al. ${ }^{11}$ & $M L H 1$ & 15 & 19 & 79 & 15 & 19 & 79 \\
\hline Hoedema et al. ${ }^{13}$ & $M L H 1$ & 1 & 1 & 100 & 1 & 1 & 100 \\
\hline Luo et al. ${ }^{122}$ & $M L H 1$ & 0 & 2 & 0 & 0 & 2 & 0 \\
\hline Niessen et al. ${ }^{15}$ & $M L H 1$ & 6 & 8 & 75 & 6 & 7 & 86 \\
\hline Plevova et al. ${ }^{18}$ & $M L H 1$ & 11 & 13 & 85 & 12 & 13 & 92 \\
\hline Southey et al. ${ }^{19}$ & $M L H 1$ & 5 & 5 & 100 & 5 & 5 & 100 \\
\hline All & MLH1 & 47 & 58 & $78(65-88)$ & 48 & 56 & $83(65-93)$ \\
\hline Barnetson et al. et al. ${ }^{10}$ & $\mathrm{MSH} 2$ & 9 & 12 & 75 & 9 & 11 & 82 \\
\hline Hendriks et al. ${ }^{11}$ & MSH2 & 10 & 10 & 100 & 10 & 10 & 100 \\
\hline Hoedema et al. ${ }^{13}$ & $\mathrm{MSH} 2$ & 4 & 4 & 100 & 4 & 4 & 100 \\
\hline Luo et al. ${ }^{122}$ & $\mathrm{MSH} 2$ & 1 & 1 & 100 & 1 & 1 & 100 \\
\hline Niessen et al. ${ }^{15}$ & $\mathrm{MSH} 2$ & 8 & 8 & 100 & 8 & 8 & 100 \\
\hline Plevova et al. ${ }^{18}$ & $\mathrm{MSH} 2$ & 2 & 4 & 50 & 2 & 4 & 50 \\
\hline Southey et al. et al. ${ }^{19}$ & $\mathrm{MSH} 2$ & 2 & 2 & 100 & 2 & 2 & 100 \\
\hline All & MSH2 & 36 & 41 & $80(62-90)$ & 36 & 40 & $83(65-92)$ \\
\hline Barnetson et al. ${ }^{10}$ & MSH6 & 3 & 6 & 50 & 3 & 4 & 75 \\
\hline Hendriks et al. ${ }^{11}$ & MSH6 & 3 & 4 & 75 & 3 & 4 & 75 \\
\hline Niessen et al. ${ }^{15}$ & MSH6 & 6 & 8 & 75 & 6 & 7 & 86 \\
\hline Plaschke et al. ${ }^{17}$ & MSH6 & 14 & 17 & 82 & 14 & 16 & 88 \\
\hline Southey et al. ${ }^{19}$ & MSH6 & 2 & 2 & 100 & 2 & 2 & 100 \\
\hline All & MSH6 & 28 & 37 & 74 (57-86) & 28 & 33 & $83(66-93)$ \\
\hline All MMR mutations & & 111 & 136 & $77^{c}(69-84)$ & 112 & 129 & $83^{c}(75-89)$ \\
\hline
\end{tabular}

${ }^{a}$ For "strict" interpretation, assay failures and one result identified as "present but reduced" (Plevova et al. ${ }^{18}$ ) are considered incorrect.

${ }^{b}$ For "less strict" interpretation, assay failures are not counted and one result identified as "present but reduced" is considered correct.

${ }^{c}$ Estimated using a random effects model.

Table 4 Clinical specificity of immunohistochemical (IHC) testing among colorectal cancer (CRC) patients without Lynch syndrome

\begin{tabular}{|c|c|c|c|c|}
\hline \multirow[b]{2}{*}{ Reference } & \multicolumn{2}{|c|}{ No. controls } & \multirow[b]{2}{*}{ Clinical specificity (\%) } & \multirow[b]{2}{*}{ FPR $(\%)$} \\
\hline & Tested & Positive $^{a}$ & & \\
\hline Barnetson et al. ${ }^{10}$ & 359 & 39 & 88 & 12.1 \\
\hline Pinol et al. ${ }^{34}$ & 1211 & 73 & 94 & 6.0 \\
\hline Cunningham et al. ${ }^{33}$ & 250 & 51 & 80 & 20.4 \\
\hline All & 1783 & 163 & $88.8^{b}(67.6-94.8)$ & $11.2^{b}(5.2-22.4)$ \\
\hline
\end{tabular}

${ }^{a}$ It was not possible to determine whether some of the individuals might have absent staining for two or more MMR genes.

${ }^{b}$ Estimated using a random effects model.

tions, the overall proportions were 32\% MLH1, 39\% MSH2, $14 \%$ MSH6, and $15 \%$ PMS2. Although based on small numbers from only one or two studies, it is interesting that slightly over one quarter of the MMR gene mutations identified occur on the MSH6 and PMS2 genes. In the future, it is likely that even more markers for detecting Lynch syndrome will be identified as more comprehensive DNA analyses become possible, and this missing information could be expressed by having the four MMR gene proportions add up to $<100 \%$. Because of the lack of information regarding which gene(s) might have future mu- 
Table 5 Estimating the proportion of Lynch syndrome attributable to each of the four major mismatch repair genes

\begin{tabular}{|c|c|c|c|c|c|}
\hline \multirow[b]{2}{*}{ Study } & \multicolumn{4}{|c|}{ Mismatch repair gene } & \multirow[b]{2}{*}{ Total } \\
\hline & $M L H 1$ & MSH2 & MSH6 & PMS2 & \\
\hline Barnetson et al. ${ }^{10}$ & $15(94 \%)^{a}$ & $16(100 \%)$ & $7(44 \%)$ & nd & 38 \\
\hline Pinol et al. ${ }^{34}$ & $4(57 \%)$ & $7(100 \%)$ & nd & nd & 11 \\
\hline Hampel et al. ${ }^{37}$ & $5(38 \%)$ & $13(100 \%)$ & $3(23 \%)$ & $5(38 \%)^{b}$ & 26 \\
\hline Cunningham et al. ${ }^{33}$ & $4(133 \%)$ & $3(100 \%)$ & nd & nd & 7 \\
\hline Weighted proportion ${ }^{c}$ & $32 \%$ & $39 \%$ & $14 \%$ & $15 \%$ & \\
\hline Salovaara et al. ${ }^{35}$ & 17 & 1 & nd & nd & $18^{d}$ \\
\hline Aaltonen et al. ${ }^{38}$ & 9 & 2 & nd & nd & $11^{c}$ \\
\hline
\end{tabular}

${ }^{a}$ Number of observations (proportion relative to number of $M S H 2$ mutations).

${ }^{b}$ Three additional deleterious PMS2 mutations identified after publication (H Hampel, personal communication).

${ }^{c}$ After accounting for the total of all weights, so the sum of the proportions would be $100 \%$.

${ }^{d}$ Study not in the analysis because of the high frequency of an $M L H I$ founder mutation in Finland.

tation/deletions/rearrangements identified, however, we have chosen to represent the distribution of MMR gene mutations among those currently identifiable (i.e., add up to $100 \%$ ).

All four studies used in determining the distribution of MMR genes are of lower quality (Level 3 or 4). Only one of them identified PMS2 mutations, and the estimated proportion of mutations in this gene is provided with the least confidence. Overall, the quality of evidence is inadequate given the small numbers involved. The distribution of MMR genes would be more important if MSI were to be the preliminary test, as the sensitivity has been shown to be lower for MSH6 mutations. The distribution is less important if IHC is the preliminary test, as the sensitivity is constant over the range of MMR genes. Fewer data are available for the performance of either test to detect PMS2 mutations.

\section{Testing for the BRAF V600E mutation}

Somatic $B R A F$ mutations have been detected in various cancers, including melanoma and CRC. About $90 \%$ of the mutations in the BRAF gene are accounted for by a transversion at nucleotide position $1799(1799 \mathrm{~T}>\mathrm{A})$ identified as V600E. The majority of CRCs with $B R A F$ V600E mutations are associated with MSI positive results. Nearly always, a deleterious MMR gene mutation (i.e., Lynch syndrome) is not present when the BRAF V600E mutation is identified. There is a strong relationship between the V600E mutation and hypermethylation of the MLH1 MMR gene. MLH1 is by far the most common MMR gene to be associated with absent IHC staining, because of the high proportion of these tumors with associated hypermethylation. Researchers have hypothesized that performing $B R A F$ testing on tumors with absent MLH1 staining might identify a group that is nearly entirely composed of sporadic $\mathrm{CRC}$ that would not benefit from $M L H 1$ sequencing. This would result in important cost savings, as $B R A F$ testing is relatively inexpensive in comparison to direct sequencing of $M L H 1$.

\section{Sensitivity and specificity of BRAF mutation testing}

Among the subpopulation of newly diagnosed CRC patients that has absent MLH1 staining, two mutually exclusive groups can be defined: (1) Lynch syndrome (those with a MMR gene mutation) and (2) sporadic cancer (those without a MMR gene mutation). In this subpopulation, the V600E BRAF mutation identifies sporadic cancer (not Lynch syndrome). Sensitivity, therefore, is defined as the proportion of sporadic cancers as- sociated with the $B R A F$ mutation. Specificity is defined as the proportion of Lynch syndrome cases without the $B R A F$ mutation. In this scenario, specificity needs to be very high so that individuals with Lynch syndrome will be offered MLH1 sequencing and not be categorized as having sporadic cancers.

Four published studies provide some information on the sensitivity and specificity of $B R A F$ testing for sporadic cancer among individuals with absent MLH1 staining. All are relatively small studies with important deficiencies. The results are summarized in Table 6 .

- Wang et al., 2003, reported on 293 patients with CRC who were selected because of their high risk of having Lynch syndrome. Of the 293, 170 tumors were MSI-stable, and the subset of these patients whose tumor was tested for IHC all showed present MLH1 and/or MSH2 staining. All absent IHC stains were in patients with MSI-high test results. Among the 60 tumors with absent MLH1 staining, 15 had germline mutations identified. One of these was a missense mutation that was not likely to have been deleterious, and this patient was found to have the $B R A F$ mutation. No BRAF mutations were found among the remaining 14 Lynch syndrome patients, yielding a specificity of $14 / 14$ or $100 \%$ (95\% CI, 77-100\%). Among the remaining 45 patients with sporadic cancers, 34 had the $B R A F$ mutation, yielding a sensitivity of $76 \%(95 \% \mathrm{CI}$, $60-87 \%)$. Although the two populations were well defined, all individuals were considered to be at high risk of Lynch syndrome and, therefore, may not represent the findings from the general population.

- Loughrey et al., 2007, reported on a subset of 500 CRC cases referred for suspicion of HNPCC to a cancer center in Australia. Tumors from 68 of these cases were identified with either a MSI-high or negative IHC stain, and there was also sufficient tumor tissue for $B R A F$ mutation testing. MLH1 staining was absent in 40 of the tumors, and all were MSI-high. Ten of these had a germline MLH1 mutation identified (Lynch syndrome), and none had the $B R A F$ mutation (specificity 10/10, 100\%, 95\% CI, 69$100 \%$ ). Only 23 of the remaining 30 tumors with absent MLH1 staining had been sequenced for germline MLH1 mutations. None had a mutation identified (i.e., sporadic cancer), and 11 of these had the BRAF mutation identified (sensitivity 48\%, 95\% CI, 27-69\%). Although the two 
Table 6 Sensitivity and specificity of BRAF mutation testing to identify sporadic colorectal cancer among all CRC cases with absent IHC staining for MLH1

\begin{tabular}{|c|c|c|}
\hline Study & Sensitivity $^{\mathrm{a}}(\%)$ & Specificity $^{\mathrm{b}}(\%)$ \\
\hline Wang et al. ${ }^{124}$ & $34 / 45,76 \%$ & $14 / 14,100 \%$ \\
\hline Loughrey et al. ${ }^{125}$ & $11 / 23,48 \%$ & $10 / 10,100 \%$ \\
\hline Kambara et al. ${ }^{126}$ & $35 / 46,76 \%$ & $18 / 18,100 \%$ \\
\hline All $^{c}$ & $\mathbf{8 0} / \mathbf{1 1 4}, \mathbf{6 8 \%}(95 \%$ CI $50-82 \%)$ & $\mathbf{4 2 / 4 2}, \mathbf{1 0 0} \%(95 \%$ CI $92-100 \%)$ \\
\hline Columbus, Ohio $^{d}$ & $25 / 36,69.4 \%$ & $8 / 8,100 \%$ \\
\hline All & $\mathbf{1 0 3 / 1 4 6 ,} \mathbf{6 9 \%}(95 \%$ CI $57-79 \%)$ & $\mathbf{5 0 / 5 0 ,} \mathbf{1 0 0 \%}(95 \%$ CI $93-100 \%)$ \\
\hline
\end{tabular}

populations were well defined, all individuals were considered to be at high risk of Lynch syndrome and, therefore, may not represent the findings from the general population.

- Kambara et al., 2004, reported on 18 cases of HNPCC (likely to be Lynch syndrome, but the report did not identify a mutation in all instances) and 46 cases with "sporadic cancers" whose tumors were classified as both MSI-high and MLH1 IHC stain negative. The 46 cases were classified as sporadic, because of a negative family history and age of onset of 56 years or later. Among the 18 cases of reported HNPCC, none of the tumors carried the $B R A F$ mutation. If these were considered to have Lynch syndrome, the specificity is $100 \%$ (95\% CI, 81-100\%). Among the 46 sporadic cases of CRC, 35 carried the $B R A F$ mutation (76\% sensitivity, 95\% CI, 61-87\%). Neither of these two groups was properly defined.

- Jensen et al., 2007, reported on 262 consecutive CRC cases (low risk of Lynch syndrome) that were tested for MSI and IHC expression. In such a group, eight individuals might be expected to have Lynch syndrome. All tumors were also tested for the BRAF mutation. Two hundred twenty-three of the tumors $(85 \%)$ had stable or low MSI test results and positive staining for both MLH1 and MSH2, and all were negative for the $B R A F$ mutation. It was assumed that none of these patients had Lynch syndrome. Tumors from all of the remaining 39 patients were MSI-high, with 32 also having an MLH1 IHC negative stain and an identified $B R A F$ mutation. Tumors from the remaining seven patients did not have a $B R A F$ mutation, meaning that a MMR gene mutation was likely to be present; four had negative MLH1 stains, two had negative $\mathrm{MSH} 2$ stains, and one was negative for both. This study cannot provide any direct estimate of $B R A F$ mutation testing specificity, as none of the individuals had been sequenced for MMR gene mutations. However, the results from this population-based study could easily be consistent with the sensitivity and specificity estimates derived from the previous three studies that were in a high-risk population.

- Additional supporting information on the very high $B R A F$ mutation testing specificity (proportion of Lynch syndrome not having the $B R A F$ mutation) can be obtained from other published studies that did not perform IHC testing. For example, if a study reports that none of 40 Lynch syndrome patients were found to have the $B R A F$ mutation, then the specificity (as defined earlier) must have been $100 \%$, even though the actual number of tumors with absent MLH1 staining is not known. In seven studies, no $B R A F$ mutations were found among 105 cases of Lynch syndrome with deleterious $M L H 1$ mutations. Some of these studies, however, enrolled only subjects whose tumors were MSI-high (most of whom would have had absent stains) and/or had a positive family history. Regardless, this provides some additional support that the specificity approaches $100 \%$. These studies also tended to enroll subjects at high risk of Lynch syndrome and, therefore, may not represent the findings in the general population.

\section{Gray data supporting the estimates of BRAF sensitivity and specificity}

Additional recruitment and molecular studies were performed after the publication of a population-based study of $\mathrm{CRC}$ and Lynch syndrome in the Columbus, $\mathrm{OH}$ catchment area (personal data provided by Dr. Albert de la Chapelle and Ms. Heather Hampel). Among a population-based cohort of 500 newly diagnosed CRC cases, 483 individuals had their tumor tested via IHC for absence of MLH1, MSH2, MSH6, and PMS2 protein. Of these 483 individuals, 71 (14.7\%) had absent staining (abnormal result); 56 also were MSI-high. In 48 of the 71 tumors $(58 \%, 95 \%$ CI, 44-64\%), MLH1 staining was absent. Sequencing of exon 15 of the $B R A F$ gene (which includes the V600E mutation) was successful for 39 of the 48 (81\%) tumors. Two had insufficient tissue, and seven failed (causes for the failures were not reported). Three of the 39 individuals were identified as having Lynch syndrome associated with an $M L H 1$ mutation. All three were negative for the $B R A F$ mutation. As part of an earlier recruitment, five additional tumors from patients with germline $M L H 1$ mutations were identified and tested for the $B R A F$ mutation; no $B R A F$ mutations were found. Thus, the specificity of $B R A F$ mutation testing in this series, overall, was $8 / 8(100 \%, 95 \%$ CI, 63-100\%). Of the remaining 36 "sporadic" cancers, 25 had the BRAF mutation, yielding a sensitivity of $69 \%$ (95\% CI, 52-84\%). Identification of Lynch syndrome is close to complete in this series. Sequencing and multiplex ligation-dependent probe amplification testing were performed on all patients with an abnormal IHC result and/or an MSI-high result. All remaining individuals were tested for the two most common large MMR gene deletions, but none were identified. In this population-based cohort, the sensitivity of $69 \%$ and specificity of $100 \%$ are nearly identical to the sum- 
mary estimates of the literature from high-risk populations (68\% and $100 \%$, respectively, from Table 6$)$.

All of the published studies are in high-risk populations and are assigned a quality rank of 2 or 3 . However, the results are homogeneous. For this reason, we sought gray data to provide evidence that the published estimates would be applicable in the general population. Given the consistency between the published and gray data, the quality of evidence for sensitivity and specificity is adequate.

\section{Is methylation testing of the MLH1 promoter region useful?}

This supplemental evidence review did not involve a formal search or statistical summary concerning the literature on methylation testing. The literature suggests, however, that $B R A F$ V600E mutation testing and methylation testing of the MLH1 promoter region among CRC cases with absent MLH1 protein might avoid similar numbers of sequencing tests with little loss in Lynch syndrome detection. ${ }^{37,39-43}$

\section{Benefits and harms to probands and relatives identified with lynch syndrome}

\section{Should informed consent be applied to all individuals with CRC before MSI or IHC testing?}

Informed consent issues were not discussed in the original evidence report. The process of identifying the subset of individuals with Lynch syndrome from among those with CRC is most appropriately accomplished by a judicial, stepwise application of informed consent. ${ }^{44}$ Two possible options can be considered for informing CRC patients about testing for Lynch syndrome: (1) counsel everyone at the outset, or (2) perform MSI or IHC testing as part of routine practice without consent and reserve counseling for those whose test results indicate that mutation testing be considered. The first option assures that choices are possible for every aspect of the testing process. However, most $(97 \%$ or $98 \%)$ of these patients would receive counseling about Lynch syndrome that is not relevant for their situation, and these same patients would worry about a medical condition that they would be found not to have. The second option does not allow choices about MSI or IHC testing, but instead limits the focus of attention to those with abnormal MSI or IHC results. This is because counseling is directed only at CRC patients with positive preliminary test results, including the $2-4 \%$ of patients whose cancers are due to a mutation in a MMR gene. In addition, those with MSI or IHC test results that indicate consideration of mutation testing retain the ability to decide about the most critical choices - definitive mutation testing and transmitting information to other family members.

There are some who feel that IHC testing is analogous to genetic testing, because individuals with results indicating the absence of MSH2 and/or MSH6, or PMS2 staining in their tumor are highly likely to have a germline mutation in these genes. However, patients with abnormal IHC results are not obliged to pursue genetic testing unless they choose to do so, and there are patients with absence of these proteins in their tumors who do not have an identifiable mutation in the corresponding gene. This could be compared to performing estrogen receptor (ER), progesterone receptor (PR), and HER-2/neu (a gene that plays a key role in the regulation of normal oncogene cell growth) testing on breast cancer patients. It is known that patients with triple negative $(\mathrm{ER}-, \mathrm{PR}-$, and her-2/neu-) breast cancers have a high likelihood of carrying a $B R C A 1$ gene mutation; however, informed consent is not needed for these tests, as they affect prognosis and management. ${ }^{45}$ There are clear data indicating that MSI status affects the prognosis for CRC patients, but not management. ${ }^{46,47}$ It has been proposed that a waiver of consent to perform MSI and IHC screening be considered for individuals with CRC. Although it is beyond the scope of this review to make recommendations regarding questions of informed consent for MSI and IHC testing, it is hoped that this presentation of evidence from both perspectives may help to inform the decision making of those in health policy domains, where these issues must ultimately be weighed.

\section{How is management of CRC influenced when an individual is known to have Lynch syndrome?}

Testing for Lynch syndrome is becoming more commonplace, and some institutions have begun screening using IHC or MSI on biopsy or surgical specimens. Also, rectal cancer patients often receive neoadjuvant chemotherapy and radiation therapy, allowing time for counseling and genetic testing before surgery and/or chemotherapy. As a result, surgical and oncological care of newly diagnosed CRC patients may be influenced by knowledge that a patient has Lynch syndrome. Subtotal colectomy with ileorectal anastomosis is recommended as a reasonable choice to be presented to patients with Lynch syndrome as the preferred surgery at the time of diagnosis with CRC. Although favored, it has not been proven superior to segmental resection with follow-up colonoscopic surveillance (category of evidence III, Grade C), based on a nonexperimental, descriptive study, ${ }^{48}$ insufficient evidence, ${ }^{49}$ and a 2006 multisociety evidence review of risk-reducing surgeries in inherited cancers. ${ }^{50}$ Patients with rectal cancers should be offered proctocolectomy with ileal pouch anal anastomosis or anterior proctosigmoidectomy with primary reconstruction. ${ }^{50}$

Persons with CRC and Lynch syndrome have a $16 \%$ risk for developing a second primary CRC within 10 years of their first diagnosis. ${ }^{38}$ This influences the above recommendation for subtotal colectomy, instead of segmental resection with follow-up colonoscopy. A decision analysis study found that subtotal colectomy, in Lynch syndrome patients younger than 47 years, who have been diagnosed with CRC, leads to a 1-2.3 year increase in life expectancy. ${ }^{51}$ This was not adjusted based on quality of life, because there were no data available on quality of life differences after these surgeries among individuals with Lynch syndrome. Among patients with sporadic CRC, segmental resection has been shown to result in better quality of life than subtotal colectomy, but this may be offset by the need for frequent, lifelong colonoscopy and fear of CRC among persons with Lynch syndrome. ${ }^{48}$ Surgical risks of subtotal colectomy with ileorectal anastomosis are discussed later.

No alteration in chemotherapeutic management is currently recommended in CRC patients with Lynch syndrome. Both laboratory and clinical studies, though few in number, find that MSI-high tumors are resistant to fluorouracil (5-FU)-based chemotherapy and are more sensitive to CPT11 (irinotecan). ${ }^{52,53}$ Prospective clinical trials are needed, however, before altering the care of CRC patients with Lynch syndrome. If this finding is confirmed, MSI or IHC testing (as a surrogate for MSI) will likely become standard in the pathologic evaluation of all CRCs.

The reviews discussed above ${ }^{48-50}$ were not available at the time the original evidence report was performed. However, no prospective trial results for clinical management options for Lynch syndrome patients have been published since that report's completion. 
Table 7 Number of family members at risk for Lynch syndrome and the proportion who underwent genetic counseling and testing

\begin{tabular}{|c|c|c|c|c|c|}
\hline \multirow[b]{2}{*}{ Study } & \multicolumn{2}{|c|}{ No. } & \multirow[b]{2}{*}{$\mathrm{x} / \mathrm{y}$} & \multicolumn{2}{|c|}{ No.(\%) relatives } \\
\hline & Probands (y) & Relatives (x) & & Counseled & Tested \\
\hline Aktan-Collan et al. ${ }^{127}$ & Unknown & 286 & Unknown & $113(39)$ & $112(99)$ \\
\hline Hampel et al. ${ }^{37}$ & 21 & $234^{a}$ & 11 & $119(51)$ & $117(98)$ \\
\hline Hadley et al. ${ }^{128}$ & 54 & 111 & 2.1 & $57(51)$ & $56(98)$ \\
\hline Aktan-Collan et al. ${ }^{54}$ & 36 & 446 & 12 & $347(78)$ & $334(96)$ \\
\hline Stanley et al. ${ }^{129}$ & 1 & 96 & 96 & $41(43)$ & $39(95)$ \\
\hline Lerman et al. ${ }^{130}$ & 4 & 208 & 52 & $92(44)$ & $84(91)$ \\
\hline Codori et al. ${ }^{131}$ & 118 & 505 & 4.2 & $104(21)^{b}$ & $96(92)$ \\
\hline Total $(95 \% \mathrm{CI})$ & 234 & 1886 & & 873 (52) (34-69) & 732 (95) (93-97) \\
\hline
\end{tabular}

${ }^{a}$ Personal communication, H. Hampel.

${ }^{b}$ An additional 129 were pending counseling — not included in the summary counseling rate.

\section{How many family members of individuals with Lynch syndrome might be identified, counseled, and choose to be tested?}

Table 7 summarizes studies that report the number of relatives at risk for Lynch syndrome, the number receiving genetic counseling, and the number undergoing genetic testing. One thousand eight hundred eighty-six relatives of 234 individuals with Lynch syndrome (eight per proband) were identified. This is likely to be an overestimate of the numbers of relatives actually approached as part of a screening program, as some studies targeted large families for study. If the two studies that targeted large families are removed, the remaining four studies provide estimates ranging from 2.1 to 12 first-degree relatives approached. The wide discrepancy is likely due to the amount of effort and resources, and the technique applied to identifying, contacting, and approaching relatives. Genetic counseling, for example, may only be offered at a central site requiring patient travel, or counselors might travel to family events such as reunions to maximize availability. Although not reported, there would likely be at least as many second-degree relatives.

Among the total number of 1886 relatives identified, 873 or $52 \%(95 \%$ CI, 37-66\%) were counseled. The resulting analysis showed heterogeneity $(Q=130, P<0.001)$, mainly due to the later study by Aktan-Collan et al. ${ }^{54}$ With this study removed, the consensus estimate is $46 \%(95 \% \mathrm{CI}, 41-50 \%)$. Among those receiving counseling, 732 or $95 \%$ (95\% CI, 93-97\%) underwent genetic testing. These results were homogeneous $(Q=12, P=$ 0.06). Gene testing offers possible benefits and harms to blood relatives of individuals with Lynch syndrome, whether the results are positive or negative. Those relatives found to carry a MMR gene mutation are encouraged to comply with increased surveillance (e.g., colonoscopy). ${ }^{55}$ Those who do not carry a MMR gene mutation may derive psychological benefits (see next section) and can follow surveillance recommendations for the general population.

Although the original evidence report summarized factors that might affect the acceptance of genetic testing, it did not estimate the number of family members of Lynch syndrome patients that could be identified, nor did it estimate the uptake of genetic counseling and testing by family members.

\section{What information exists about insurance concerns?}

Few publications report data on worry about insurance and/or employment due to MMR gene mutation testing results. In one study, 90 women were referred for predictive genetic testing (MMR or BRCA1/2). ${ }^{56}$ One woman $(1 \%, 95 \%$ CI, $1-6 \%)$ chose not to pursue genetic testing, because of concerns regarding future insurance and employment implications. Another study invited patients who met either the Amsterdam or the Bethesda criteria, and their families, to participate in genetic counseling and testing after MMR gene testing became available. ${ }^{57}$ Of the 23 patients and family members who chose to participate, $18 \%$ were concerned about problems with insurance and/or employers, compared with $33 \%$ of the 48 nonparticipants who returned a questionnaire.

This question was not directly addressed by the original evidence report. Both studies summarized above, however, were included. The insurance concern cited in the study by Arver et al. ${ }^{56}$ was part of the report (original evidence reportTable 26). The study by Keller et al. ${ }^{57}$ was summarized in Extra Table 1 in the original evidence report, however, no mention was made regarding insurance concerns. In May 2008, the Genetic Information Nondiscrimination Act was signed into law. This bill is designed to protect Americans against discrimination based on their genetic information when it comes to health insurance and employment.

\section{What are the future cancer risks (penetrance) among carriers of a MMR mutation?}

Relevant findings from studies mentioned in this section are summarized in Table 8 . Recent data suggest a colon cancer risk ranging between $22 \%$ and $58 \%$ by age 70 for individuals with a MMR mutation. ${ }^{58,59}$ Based on all available data, reasonable estimates for penetrance by age 70 might be $45 \%$ for men, and $35 \%$ for women. These penetrance estimates are lower than previously thought. One likely explanation is that more recent studies tend to be population based. Earlier studies focused on families with many affected members, where risk might be intensified by other genetic and environmental influences. A review in 2002 exemplifies the earlier thinking about penetrance. ${ }^{60}$ It documented a consistent finding among seven studies that risk for colon cancer by age 70 years is higher among male $M L H 1$ and $M S H 2$ mutation carriers (80\%) than 
Table 8 Risk of cancers by age 70 among relatives with Lynch syndrome

\begin{tabular}{|c|c|c|c|c|c|c|}
\hline \multirow[b]{2}{*}{ Study } & \multirow[b]{2}{*}{ Number evaluated } & \multicolumn{2}{|c|}{$M L H 1 / M S H 2$} & \multicolumn{2}{|c|}{$\begin{array}{c}\text { MLH1/MSH2/MSH6/ } \\
\text { PMS2 }\end{array}$} & \multirow{2}{*}{$\begin{array}{c}\text { MSH6 } \\
\text { Males + females }\end{array}$} \\
\hline & & Males & Females & Males & Females & \\
\hline \multicolumn{7}{|c|}{ Colorectal cancer (males and females) } \\
\hline Vasen et al. ${ }^{66}$ & 382 & $92^{a}$ & $68^{a, b}$ & & & \\
\hline Dunlop et al. ${ }^{132}$ & 1563 & 100 & 54 & & & \\
\hline Aarnio et al. ${ }^{64}$ & 156 & 74 & 30 & & & \\
\hline Vasen et al. ${ }^{63}$ & 3222 & 69 & 54 & & & \\
\hline Hampel et al. ${ }^{65}$ & 373 & 69 & 52 & & & \\
\hline Quehenberger et al. ${ }^{58}$ & 2392 & 27 & 22 & & & \\
\hline Jenkins et al. ${ }^{59}$ & 97 & & & 45 & 38 & \\
\hline Wagner et al. ${ }^{62}$ & 80 & & & & & $32^{a}$ \\
\hline Buttin et al. ${ }^{61}$ & 59 & & & & & 58 \\
\hline \multicolumn{7}{|c|}{ Endometrial cancer (females only) } \\
\hline Aarnio et al. ${ }^{64}$ & Not given & & 60 & & & \\
\hline Vasen et al. ${ }^{66}$ & Not given & & $50^{b}$ & & & \\
\hline Vasen et al. ${ }^{63}$ & Not given & & $31^{b}$ & & & \\
\hline Hampel et al. ${ }^{65}$ & 183 & & 54 & & & \\
\hline Quehenberger et al. ${ }^{58}$ & Not given & & 32 & & & \\
\hline Wagner et al. ${ }^{62}$ & 53 & & & & & $52^{a}$ \\
\hline Buttin et al. ${ }^{61}$ & Not given & & & & & $64^{a}$ \\
\hline
\end{tabular}

${ }^{a}$ To age $80 \mathrm{yr}$.

${ }^{b}$ Estimated from data given.

among females $(40 \%)$. By contrast, a cohort study of colon cancer cases diagnosed before age 45 years, reported in 2006, cites a lower risk for colon cancer among men (45\%), but still finds a reduced risk among women $(38 \%) .{ }^{59}$ This study included MLH1, MSH2, MSH6, and PMS2 mutation carriers and suggested that CRC risk may be $10 \%$ lower for MSH6 and PMS2 mutation carriers than for MLH1 and MSH2. This finding is supported by two studies that show the risk for colon cancer in carriers of MSH6 mutations to be $58 \%$ and $32 \%$ by age 80 , respectively. ${ }^{61,62}$ Reanalysis of data that adjusted for the ascertainment of cases collected from a previous study ${ }^{63}$ showed that the cumulative risk for CRC among $M L H 1$ or $M S H 2$ mutation carriers is $27 \%$ for men and $22 \%$ for women, by age 70 years. ${ }^{58}$ There is a great deal of inconsistency among data pertaining to this question. Because of the heterogeneity of population sampling, MMR genes tested and other variables, it is not possible to create a single summary estimate. There are, however, two consistent findings. First, in all studies, females have a lower risk of developing $\mathrm{CRC}$ than their male counterparts, usually by $20-40 \%$. Second, there is a clear trend toward lower penetrance estimates when studies are population based. Using these two findings, reasonable estimates for penetrance by age 70 might be $45 \%$ for men, and $35 \%$ for women. It should be noted that our analyses have been focused primarily upon cohort, and generally on more recent studies, that attempt to avoid the "high-risk family" biases.

The risk for other Lynch syndrome-related cancers (e.g., endometrial, stomach, and brain) has been estimated to be $22 \%$ for men and $34 \%$ for women, up to age 70 years. ${ }^{59}$ The gender difference is mainly due to the risk of endometrial cancer in women, and it may be possible to impact the incidence by screening and/or risk-reducing activities (discussed later). The proportion of female $\mathrm{MLH1} / \mathrm{MSH} 2$ mutation carriers that develops endometrial cancer by age 70 has been reported in five studies summarized in Table 8. ${ }^{58,63-66}$ The estimates range from around $30 \%$ to $60 \%$. The proportion of female MSH6 mutation carriers that develops endometrial cancer by age 80 seems to be similar, at 52\% and 64\%. ${ }^{61,62}$ These estimates seem high compared with the overall rates of Lynch syndrome-related cancers. A recent methodological study ${ }^{67}$ suggests that the studies on the risk of endometrial cancer among relatives may also suffer from the same bias of strong family history discussed for CRC. Overall, the penetrance for endometrial cancer by age 70 in the general Lynch syndrome population may be as low as $20-25 \%$.

\section{What are the recommended frequency, uptake, and risks of $C R C$ surveillance among carriers of a $M M R$ mutation?}

A recent literature review evaluated how predictive testing affects surveillance/screening behaviors. ${ }^{68}$ Uptake of colonoscopy for MMR mutation carriers was high in six ${ }^{69-75}$ of seven studies, ranging from $53 \%{ }^{76}$ to $100 \%$ (top half of Table 9). Five studies reported the uptake of colonoscopy within 1-2 years after receiving genetic test results, ${ }^{69-71,74,76}$ the other two studies reported the uptake of colonoscopy since receiving their 
Table 9 Proportion of relatives with Lynch syndrome who comply with surveillance

\begin{tabular}{lcc}
\hline Study & No. carriers & No. (\%) having \\
\hline Colorectal cancer surveillance & 17 & Colonoscopy \\
Hadley et al. ${ }^{76}$ & 21 & $9(53)$ \\
Collins et al. ${ }^{70}$ & 22 & $15(71)$ \\
Halbert et al. ${ }^{71}$ & 7 & $16(73)$ \\
Johnson et al. ${ }^{72}$ & 23 & $7(100)$ \\
Ponz de Leon et al. ${ }^{74}$ & 36 & $18(78)$ \\
Claes et al. ${ }^{69}$ & 42 & $33^{a}(100)$ \\
Wagner et al. ${ }^{75}$ & $\mathbf{1 6 8}$ & $37(88)$ \\
Total $(95 \%$ CI) & & $\mathbf{1 3 5}(\mathbf{7 9})^{\boldsymbol{a}}$ \\
Endometrial cancer surveillance & & $(67-87 \%)$ \\
Wagner et al. ${ }^{75}$ & 29 & TVU/biopsy \\
\cline { 2 - 3 } Collins et al. ${ }^{70}$ & 17 & $20(69)$ \\
Total $(95 \%$ CI) & $\mathbf{4 6}$ & $9(53)$ \\
& & $\mathbf{2 9}(\mathbf{6 3})^{b}$ \\
$(46-75 \%)$
\end{tabular}

${ }^{a}$ Three mutation carriers were under age 25 and, therefore, were not recommended to have a colonoscopy.

${ }^{b}$ Three mutation carriers were under age 25 and, therefore, were not recommended to have endometrial cancer surveillance.

genetic test results. ${ }^{72,75}$ Overall, the average uptake rate was $79 \%$ (95\% CI, 67-87\%) with some evidence of heterogeneity ( $Q=14, P=0.03)$. This is due to the study of Hadley et al. $(53 \%) .{ }^{76}$ If that study were to be removed, the uptake rate would be $81 \%(95 \%$ CI, $72-87 \%)$ with no evidence of heterogeneity
$(Q=8, P=0.2)$. Two recent reviews regarding clinical management of individuals with Lynch syndrome ${ }^{48,49}$ reached similar conclusions regarding colonoscopy surveillance for $\mathrm{CRC}$ and endometrial cancer. Colonoscopy is recommended every 1-2 years, beginning at ages $20-25.48,49,77,78$ The $1-2$ year frequency is graded level of evidence IIIC. ${ }^{48}$ Individuals with MSH6 mutations are recommended to begin colonoscopy at age 30, given the lower colon cancer risks associated with mutations in this gene. ${ }^{49}$

Colonoscopy risks include adverse events related to the bowel preparation. The most common events are nausea, abdominal pain, and dizziness, which seem to be comparable between the two most common bowel cleansing agents, sodium phosphate $(\mathrm{NaP})$ and polyethylene glycol. Biochemical changes associated with $\mathrm{NaP}$ are largely asymptomatic, but require caution in patients with cardiovascular or renal impairment. Significantly more patients are able to complete the $\mathrm{NaP}$ preparation than that for polyethylene glycol. ${ }^{79}$ There have been rare serious or fatal events from the bowel preparation. ${ }^{80}$

The most common serious, adverse events associated with the colonoscopy procedure (Table 10) are bleeding (1.1/ 1000 , 95\% CI, 0.8-1.4), perforation $(3.3 / 1000,95 \% \mathrm{CI}$, 2.3-4.6), and death (0.08/1000, 95\% CI, 0.05-0.14). ${ }^{81-92}$ Factors associated with increased risk for adverse events are female gender, increasing age, and history of surgery, or diverticular disease.

\section{Is there evidence that routine colonoscopy among carriers of a MMR mutation improves outcome?}

Although there are no randomized trials to document whether systematic surveillance is effective in reducing Lynch syndromerelated morbidity and mortality, one long-term study from Finland (begun in 1982) reports follow-up on 252 family members (age 20-66 years) of 22 index cases. ${ }^{93}$ Initially, the families were selected on the basis of family history, and 133 chose

Table 10 Adverse events related to colonoscopy

\begin{tabular}{|c|c|c|c|c|c|}
\hline \multirow[b]{2}{*}{ Study } & \multirow[b]{2}{*}{ Population } & \multirow[b]{2}{*}{ Procedures } & \multicolumn{3}{|c|}{ Complications per 1000} \\
\hline & & & Perforation & Bleeding & Deaths $^{a}$ \\
\hline Cobb et al. ${ }^{81}$ & Medical center & 43,609 & 0.32 & - & - \\
\hline Gatto et al. ${ }^{82}$ & Medicare sample over $65 \mathrm{yr}$ & 39,286 & 1.96 & - & - \\
\hline Levin et al. ${ }^{83}$ & Kaiser Permanente & 16,318 & 0.90 & 4.8 & 0.06 \\
\hline Rathgaber et al. ${ }^{84}$ & Community GI practice & 12,407 & 0.16 & - & 0.00 \\
\hline Korman et al. ${ }^{85}$ & 45 endoscopic surgery centers & 116,000 & 3.00 & - & - \\
\hline Viiala et al. ${ }^{86}$ & Australian teaching hospital & 30,463 & 1.00 & 2.1 & 0.09 \\
\hline Nelson et al. ${ }^{87}$ & VA medical centers & 3196 & 0.00 & 4.4 & 0.00 \\
\hline Dafnis et al. ${ }^{88}$ & One Swedish county & 6066 & 1.00 & 2.0 & 0.00 \\
\hline Anderson et al. ${ }^{89}$ & U.S. teaching hospital & 10,486 & 1.90 & - & 0.19 \\
\hline Zubarik et al. ${ }^{90}$ & Georgetown University Hospital & 1196 & - & $21^{b}$ & - \\
\hline Eckardt et al. ${ }^{91}$ & German gastroenterology practice & 2500 & 0.80 & 2.4 & - \\
\hline Waye et al. ${ }^{92}$ & Chapter review 1974-1994 & 99,539 & 0.45 & 4.6 & 0.06 \\
\hline All $(95 \% \mathrm{CI})$ & & 381,066 & $1.1(0.8-1.4)$ & $3.3(2.3-4.6)$ & $\mathbf{0 . 0 8}(0.05-0.14)$ \\
\hline
\end{tabular}

${ }^{a}$ Occurring within 30 days after the procedure (a total of 12 are reported in these 7 studies).

${ }^{b}$ This study used patient reports rather than physician reports, and is a referral center for high risk patients. It is not included in the summary estimate. 
colonic examination (initially at a 5-year interval, and then at 3-year intervals); 78 chose to forego colon cancer screening and 41 were not initially contacted. After 14.5 years, 8 of 133 of those who chose screening (6\%) and 19 of $119(16 \%)$ of those who chose not to be screened had developed CRC. Mutation testing became available in 1996-1998, and all of the colon cancers were found to have developed in family members who carried a mutation- 8 of $44(18 \%)$ and 19 of 46 (41\%), respectively. There were no CRC deaths among those who chose colon cancer screening, and nine among those who chose not to be screened. Overall deaths were $10(8 \%)$ in those choosing screening, and $26(22 \%)$ in those choosing not to be screened. This study reports a $62 \%$ reduction in risk for CRC and a significant reduction in CRC-associated mortality among family members of index Lynch syndrome cases who were found to carry a mutation. All results are computed using an "intention to treat" analysis. Crossover clearly occurred, with a proportion of individuals initially choosing to forgo surveillance later agreeing. This would likely result in an underestimation of the actual reduction in CRC risk among the surveillance group.

Further evidence for the efficacy of surveillance was reported recently. ${ }^{94}$ In this cohort study, 2788 members from 146 Lynch syndrome families in the Netherlands were followed to assess mortality caused by CRC. The standardized mortality ratio for CRC showed a 70\% decrease over three time periods: $1960-$ 1974, 1975-1989, and 1990-2004 $(P<0.001)$. When comparing the subjects who did $(n=897)$ or did not $(n=1073)$ have surveillance colonoscopies, a significant difference in standardized mortality ratio was observed (6.5 vs. 23.9, respectively; $P<0.001)$. Evidence for efficacy of periodic colonoscopy is graded as level IIb. ${ }^{48}$

\section{Is risk-reducing colectomy recommended for carriers of a MMR gene mutation?}

Risk-reducing colorectal resection is generally not recommended for MMR gene mutation carriers who do not have CRC (or a Lynch syndrome-related cancer). ${ }^{49,50}$ Subtotal colectomy with ileorectal anastomosis has an overall 30-day mortality rate of $0.9 \%$ and an overall 30 -day morbidity rate of $26.0 \%$. Morbidity is explained by the following complications: anastomotic leak (6.5\%), small bowel obstruction (14.4\%), fistula $(2.8 \%)$, and anastomotic stricture (1.4\%). ${ }^{95}$ Fistula and anastomotic stricture are significantly more common in patients having surgery for Crohn disease, so these risks would be lower in patients with Lynch syndrome. Median stool frequency is 3 day 1 year after surgery and does not change with longer follow-up. Among patients with familial adenomatous polyposis, the quality of life is significantly poorer than that of the general population after total colectomy with ileorectal anastomosis $(P<$ 0.001). ${ }^{96}$

The difficulty of this surgery and concerns about quality of life after surgery, combined with the efficacy of colonoscopic surveillance, leads patients to rarely choose this option. Only one study was found that assessed the uptake of risk-reducing colectomy. ${ }^{70}$ Of 32 MMR mutation carriers, none had undergone this risk-reducing surgery 12 months after receiving their mutation status. One mutation carrier indicated an intention to do so. It could be discussed as an alternative to regular colonoscopy, given the high cancer risk, concern about the safety of (or compliance with) repeated colonoscopy, and in the setting of high patient anxiety. ${ }^{68}$

\section{Is endometrial cancer surveillance recommended for women carrying a MMR gene mutation?}

More than $75 \%$ of women with a MMR gene mutation who develop endometrial cancer will be diagnosed at Stage I. However, a proportion of these women with Stage I disease will still develop metastatic disease at a later time. This is based on documentation that $10-15 \%$ of women in the general population with sporadic early stage tumors will die from metastatic disease. ${ }^{49,97}$ Transvaginal ultrasound is not highly effective at identifying endometrial cancers in women with Lynch syndrome. ${ }^{98-100}$ Endometrial biopsy, however, is effective at identifying both premalignant and malignant lesions. ${ }^{99}$ Two reviews dealing with this aspect of Lynch syndrome management reached similar conclusions. Endometrial cancer surveillance, including transvaginal ultrasound in combination with endometrial aspiration biopsy, should be performed every 1-2 years, beginning at age 30-35.48,49 The level of evidence for this surveillance guideline is IIIC. ${ }^{48}$ Transvaginal ultrasound is relatively noninvasive and inexpensive. ${ }^{98}$ In a large study using endometrial biopsy with an aspiration method, $96 \%$ of patients found the pain acceptable. ${ }^{101}$ A recent study suggests hysteroscopy with biopsy may be a feasible method to screen for endometrial cancer among women with Lynch syndrome $(n=$ $11)$ and women who meet Amsterdam II criteria $(n=46) .{ }^{102}$ Of 91 attempted hysteroscopies (10 failed), 2 endometrial carcinomas were detected. Two studies performed outside the United States assessed uptake for endometrial cancer surveillance among women. In both studies, increased adherence to surveillance was noted after genetic testing (bottom of Table 9). ${ }^{70,75}$ Overall, 63\% of women complied with endometrial cancer surveillance (95\% CI, 46-75\%).

\section{Is risk-reducing hysterectomy with bilateral salpingo- oophorectomy recommended for women carrying a MMR gene mutation?}

In a recent retrospective study, 61 of 315 women with MMR gene mutations chose risk-reducing surgery. ${ }^{103}$ The entire cohort was followed for approximately 10 years. No cases of endometrial or ovarian cancer developed in women who had risk-reducing surgery, whereas $33 \%$ of women who did not have surgery developed endometrial cancer and 5.5\% developed ovarian cancer. The two recent reviews discussed in previous sections also addressed this aspect of Lynch syndrome management and were in agreement that risk-reducing hysterectomy and bilateral salpingo-oophorectomy are not recommended, ${ }^{48,49}$ but should be presented as an option.

A second study examined preventive behaviors 1 year after genetic testing for MMR mutations. There were 21 female mutation carriers and 48 females with no mutations. When the study began, five of the women reported having had a hysterectomy, and two reported having had an oophorectomy. In the 12 months after receipt of the genetic test results, none of the women had chosen to have a hysterectomy. Two of the women who reported having had a hysterectomy at baseline chose to have a bilateral oophorectomy. No information is given on mutation status of the women who chose risk-reducing surgery. ${ }^{70}$ A larger series in a surveillance study from Finland found that $34 \%$ (59 of 175) of women with Lynch syndrome underwent a hysterectomy. ${ }^{99}$ Of these, 43 (72\%) elected surgery, because of the finding of a premalignant lesion on screening, simultaneous laparotomy for another reason, or for risk reduction.

Risks from hysterectomy (Table 11) vary depending on the surgical technique (abdominal, laparoscopic, and vaginal) but 
Table 11 Complications from hysterectomy

\begin{tabular}{|c|c|c|c|c|c|}
\hline \multirow[b]{2}{*}{ Study } & \multirow[b]{2}{*}{ Procedures } & \multicolumn{4}{|c|}{ Complication (\%) } \\
\hline & & Infection & Bleeding & Organ injury & Death \\
\hline \multicolumn{6}{|l|}{ Abdominal hysterectomy } \\
\hline Meltomaa et al. ${ }^{106}$ & 516 & 24.4 & 5.4 & 0.6 & 0 \\
\hline Makinen et al. ${ }^{105}$ & 5875 & 10.5 & 4.0 & 0.8 & 0.02 \\
\hline Olsson et al. ${ }^{107}$ & 72 & 33 & & & \\
\hline Garry et al. ${ }^{104}$ & 292 & 16.1 & 3.4 & 2.0 & 0 \\
\hline \multicolumn{6}{|l|}{ All } \\
\hline \multicolumn{6}{|c|}{ Laparoscopic hysterectomy } \\
\hline Meltomaa et al. ${ }^{106}$ & 66 & 3.0 & 9.1 & 0.7 & 0 \\
\hline Makinen et al. ${ }^{105}$ & 2434 & 9.0 & 4.7 & 2.8 & 0.04 \\
\hline Olsson et al. et al. ${ }^{107}$ & 71 & 27 & & & \\
\hline Garry et al. ${ }^{104}$ & 584 & 14.7 & 6.0 & 3.2 & 0 \\
\hline Garry et al. ${ }^{104}$ & 336 & 10.7 & 7.5 & 1.2 & 0 \\
\hline \multicolumn{6}{|l|}{ All } \\
\hline \multicolumn{6}{|l|}{ Vaginal hysterectomy } \\
\hline Meltomaa et al. ${ }^{106}$ & 66 & 3.0 & 9.1 & 0.7 & 0 \\
\hline Makinen et al. ${ }^{105}$ & 2434 & 9.0 & 4.7 & 2.8 & 0.04 \\
\hline Olsson et al. ${ }^{107}$ & 71 & 27 & & & \\
\hline All & & & & & \\
\hline
\end{tabular}

include infection (3-33\%), bleeding (3.4-9.1\%), organ injury $(0.6-3.2 \%)$, and rarely death (none observed to $0.04 \%) .104-107$ Because of the significant heterogeneity, summary estimates for complication rates were not computed. A meta-analysis of 27 trials with 3643 participants found that "return to normal activities" was quicker for vaginal compared with abdominal hysterectomy with weighted mean differences of 9.5 days $(95 \% \mathrm{CI}$, 6.4-12.6), and for laparoscopic compared with abdominal hysterectomy with weighted mean differences of 13.6 days $(95 \%$ CI, 11.8-15.4). ${ }^{108}$ There were no significant differences in return to normal activities between laparoscopic versus vaginal hysterectomy. There were more urinary tract injuries with laparoscopic than with abdominal hysterectomy (odds ratio 2.61, 95\% CI, 1.22-5.6), but no other intraoperative visceral injuries showed a significant difference between surgical approaches. One study measured subjective outcomes by questionnaire survey at 4-6 weeks and 1 year after hysterectomy. ${ }^{106}$ Although subjective complaints (including abdominal pain, urinary incontinence, menopausal symptoms, and genital prolapse) increased significantly at the 1 -year questionnaire $(P<0.001), 95 \%$ of patients reported being satisfied with the procedure.

Risks from bilateral salpingo-oophoectomy are numerous and it is beyond the scope of this article to summarize all of them. Two recent reviews on this topic have been published. ${ }^{109,110}$ Risk-reducing oophorectomy in premenopausal women induces the sudden onset of menopause. Effects may include a higher percentage of adipose tissue and lower muscle mass, adverse changes in multiple cardiovascular risk factors, higher risk of myocardial infarction, higher rates of atherosclerosis, increased risk of mortality, short-term memory declines, dementia, macular degeneration, increased risk of bone frac- tures and osteoporosis, sexual dysfunction and loss of desire, skin changes, and urogenital atrophy.

\section{What surveillance is recommended for other Lynch syndrome-associated cancers among MMR gene mutation carriers?}

There are no studies addressing surveillance for other less common Lynch syndrome-associated cancers, so the recommendation below, extracted from the two recent reviews, is based on expert opinion. Persons with Lynch syndrome should stay in contact with their physicians and report signs or symptoms immediately (one review recommends annual visits beginning at age 21 ). There are no data regarding the efficacy or compliance with this screening recommendation.

- Gastric cancer surveillance: Gastroduodenoscopy is recommended in persons with Lynch syndrome every 1-2 years, beginning at age 30-35 years, if gastric cancer runs in their family, or if they are from a country with a high incidence of gastric cancer. ${ }^{48}$ A modified recommendation is that this procedure be offered periodically, taking into consideration that there is no evidence that persons with Lynch syndrome in a family where gastric cancer has been diagnosed are at higher risk for that cancer than if there were no gastric cancer cases in the family. ${ }^{49,111}$

- Urinary tract cancer surveillance: Although there are data which indicate that urine cytology is not an effective method to screen for urinary tract cancers in patients with Lynch syndrome, currently it is recommended as an inexpensive and noninvasive surveillance modality every 1-2 
years beginning at age $25-35 \cdot 48,49,112$ Abdominal ultrasound for urinary tract cancers is also suggested at the same interval. ${ }^{48}$

\section{Anxiety and psychosocial issues \\ What is the psychosocial impact of mutation testing for family members (worry, anxiety, depression, and benefits)?}

Data pertaining to psychosocial outcomes of genetic counseling and testing have been looked at by comparing outcomes between carriers and noncarriers of MMR gene mutations, and changes in outcomes over time. Changes in distress among mutation carriers seem to be short term, and there is no indication of adverse effects of genetic testing. ${ }^{56,69,113-116}$ Unaffected noncarriers derive psychological benefits, such as short- and long-term decreases in colon cancer worry, general anxiety, and depression, ${ }^{31}$ other benefits include removal of uncertainty, assurance that offspring are not at high risk, avoidance of intensive surveillance, and removal of the threat of discrimination. ${ }^{117}$ Table 12 summarizes differences in outcomes at selected time intervals after genetic testing between mutation carriers and noncarriers.

The original evidence report noted the changes in psychosocial outcomes over time, and the differences in outcomes between mutation carriers and noncarriers. The study with the longest follow-up (3 years) ${ }^{113}$ was not available for this report. The evidence report also discussed the efficacy of pretest genetic counseling for informing family members of potential risks and benefits of testing. Psychological benefits of genetic testing were not reviewed.

\section{Other options for preliminary testing}

- Family history: The original evidence report discusses the use and limitations of both the original and revised versions of the Amsterdam criteria and the Bethesda guidelines. Both of these tools use personal and family history to either diagnose HNPCC (which some call Lynch syndrome), or to predict which patients with $\mathrm{CRC}$ are likely to have a MMR gene mutation. The Amsterdam criteria have a lower sensitivity for detecting Lynch syndrome, ranging from $54 \%$ to $91 \% .^{1}$ A series of 1066 patients with newly diagnosed CRC, regardless of age and family history, was recently studied ${ }^{37}$ Of the 23 patients identified with Lynch syndrome, $3(13 \%)$ met the Amsterdam criteria and 18 (78\%) met the Bethesda guidelines. These data show that using family history as a screening test for Lynch syndrome will likely miss a significant proportion of cases. This finding should not be construed as suggested that family history is not associated with CRC or that collecting a family history might not be valuable in the general population. Only that with the existing infrastructure, the use of routine family history is not supported by sufficient evidence to form a first-line test for Lynch syndrome among individuals with newly diagnosed CRC.

- Cut off level for age at onset of CRC: Another alternative strategy might be to offer MSI or IHC testing only to individuals with a newly diagnosed $\mathrm{CRC}$ who are under a specific age. For example, it might be possible to offer testing only to new cases whose age at diagnosis was under 70 years, given the known association between Lynch syndrome and early age of onset. This would be an efficient strategy if a high proportion of Lynch syndrome CRC cases occurred before that age (high sensitivity), whereas a relatively high proportion of sporadic CRC cases occurred after that age (high specificity). Not testing this older age group would then save resources while maintaining high detection of Lynch syndrome. A CEA would be required to properly answer this question as it involves a tradeoff between benefits and harms. Such an analysis is beyond the scope of this report.

\section{Economic modeling}

Existing economic analyses that included relatives with Lynch syndrome were reviewed and found inadequate. ${ }^{18-121}$ None included IHC or BRAF testing as part of the strategy to identify Lynch syndrome, and they did not address varying sensitivities/specificities of MSI and IHC by MMR gene mutation.

Table 12 Psychosocial outcomes in Lynch syndrome relatives compared with relatives without mutations

\begin{tabular}{|c|c|c|c|c|c|c|c|}
\hline \multirow{3}{*}{$\begin{array}{l}\text { Psychosocial } \\
\text { outcome }\end{array}$} & \multicolumn{7}{|c|}{ Finding statistically significant at } \\
\hline & \multicolumn{2}{|c|}{$2-4 \mathrm{Wks}$} & \multicolumn{2}{|c|}{ 4-6 Mo } & \multicolumn{2}{|c|}{$1 \mathrm{Yr}$} & $3 \mathrm{Yr}$ \\
\hline & Yes & No & Yes & No & Yes & No & Yes \\
\hline $\begin{array}{l}\text { Worried about } \\
\text { developing } \\
\text { cancer }\end{array}$ & Collins et al. ${ }^{113}$ & & Collins et al. ${ }^{113}$ & & $\begin{array}{l}\text { Aktan-Collan et } \\
\text { al. }{ }^{115} \text { and Collins } \\
\text { et al. }{ }^{113}\end{array}$ & & Collins et al. ${ }^{113}$ \\
\hline Anxiety & $\begin{array}{l}\text { Meiser et al. }{ }^{114} \text {, } \\
\text { Collins et } \\
\text { al. }{ }^{113} \text {, and } \\
\text { Claes et al. }{ }^{69}\end{array}$ & Arver et al. ${ }^{a_{56}}$ & & $\begin{array}{l}\text { Meiser et al. }{ }^{114} \text {, } \\
\text { Collins et } \\
\text { al. }{ }^{113} \text {, and } \\
\text { Arver et } \\
\text { al. }^{a_{56}}\end{array}$ & & $\begin{array}{l}\text { Meiser et al. }{ }^{114} \text {, } \\
\text { Collins et } \\
\text { al. }{ }^{113} \text {, and } \\
\text { Arver et } \\
\text { al. }^{a_{56}}\end{array}$ & Collins et al. ${ }^{113}$ \\
\hline $\begin{array}{l}\text { Intrusive/avoidant } \\
\text { thoughts }\end{array}$ & Meiser et al. ${ }^{114}$ & & & Meiser et al. ${ }^{114}$ & Meiser et al. ${ }^{114}$ & & \\
\hline Depression & & $\begin{array}{l}\text { Meiser et al. }{ }^{114} \text {, } \\
\text { Collins et } \\
\text { al. }{ }^{113} \text {, and } \\
\text { Arver et } \\
\text { al. }^{a 56}\end{array}$ & & $\begin{array}{l}\text { Meiser et al. }{ }^{114} \text {, } \\
\text { Collins et } \\
\text { al. }{ }^{113} \text {, and } \\
\text { Arver et } \\
\text { al. }^{a 56}\end{array}$ & Arver et al. ${ }^{a 56}$ & $\begin{array}{l}\text { Meiser et al. }{ }^{114} \\
\text { and Collins } \\
\text { et al. }{ }^{113}\end{array}$ & Collins et al. ${ }^{113}$ \\
\hline
\end{tabular}

\footnotetext{
${ }^{a}$ Includes only women with either $B R C A 1 / 2$ or MMR mutations.
} 
Table 13 Lynch syndrome: epidemiological parameters, test performance, uptake rates, and direct medical costs

\begin{tabular}{|c|c|c|c|c|c|}
\hline \multicolumn{3}{|l|}{ Epidemiological parameters } & \multicolumn{3}{|l|}{ Costs and uptake rates } \\
\hline Parameter & Source $^{a}$ & Base & Parameter & Source $^{a}$ & Base \\
\hline Newly diagnosed CRC tested & Current & 150,000 & Average number of $1^{\circ}$ and $2^{\circ}$ relatives & EO & 4 \\
\hline Prevalence of Lynch syndrome (LS) & current & $3 \%$ & Relatives accepting counseling & Current & $52 \%$ \\
\hline Proportion of LS with $M L H 1$ mutation & Current & $32 \%$ & Relatives accepting testing counseling & Current & $95 \%$ \\
\hline Proportion of LS with $\mathrm{MSH} 2$ mutation & Current & $39 \%$ & Relative with mutation testing & EO & $30 \%$ \\
\hline Proportion of LS with MSH6 mutation & Current & $14 \%$ & Cost of offering testing & EO & $\$ 20$ \\
\hline Proportion of LS with $P M S 2$ mutation & Current & $15 \%$ & Cost of $M L H 1$ sequencing/deletion analysis & M & $\$ 808$ \\
\hline Sequencing/MLPA sensitivity of LS & EO & $99.5 \%$ & Cost of $M S H 2$ sequencing/deletion analysis & M & $\$ 683$ \\
\hline Sequencing/MLPA (1 - specificity) for LS & EO & $0.03 \%$ & Cost of MSH6 sequencing & M & $\$ 983$ \\
\hline MSI sensitivity for $M L H 1 / M S H 2$ mutations & Current & $91 \%$ & Cost of MSH6 deletion analysis & M & $\$ 102$ \\
\hline MSI sensitivity for MSH6/PMS2 mutations & Current & $77 \%$ & $\begin{array}{l}\text { Cost of microsatellite instability (MSI) } \\
\text { testing }\end{array}$ & M & $\$ 457$ \\
\hline MSI specificity & Current & $9.8 \%$ & Cost of immunohistochemical (IHC) testing & M & $\$ 261$ \\
\hline IHC sensitivity for LS & Current & $83 \%$ & Cost of $B R A F$ V600E mutation testing & M & $\$ 100$ \\
\hline IHC specificity for LS & Current & $11.2 \%$ & Cost of initial counseling & M & $\$ 175$ \\
\hline IHC MSH1 absent stain (PMS2 + or - ) & $\mathrm{PC}$ & $70 \%$ & Cost of result session (positive result) & M & $\$ 95$ \\
\hline IHC MSH2 absent stain (MSH6 + or -) & $\mathrm{PC}$ & $15 \%$ & Cost of approaching $1^{\circ}$ relative & SR & $\$ 100$ \\
\hline MSH6 absent stain only & $\mathrm{PC}$ & $10 \%$ & $\begin{array}{l}\text { Cost of targeted testing in relatives } \\
\text { proband }\end{array}$ & M & $\$ 55$ \\
\hline PMS2 absent stain only & $\mathrm{PC}$ & $5 \%$ & & & \\
\hline$B R A F$ sensitivity for $\mathrm{SC}$ among IHC absent & Current & $99.5 \%$ & & & \\
\hline$B R A F$ specificity for $\mathrm{SC}$ among IHC absent & Current & $69 \%$ & & & \\
\hline
\end{tabular}

$\bar{a}$ current, this review; EO, expert opinion; M, 2007 Medicare reimbursement rates; PC, personal communication H Hampel, data from the Ohio experience; SR, Ramsey et al. ${ }^{133}$

Many possible testing strategies for identifying Lynch syndrome in a general population are possible using individual (or combinations of) preliminary tests (MSI, IHC, and BRAF mutation testing) and diagnostic tests (sequencing/deletion analysis for the three or four MMR genes). The strategies will have varying sensitivities for detecting Lynch syndrome ranging from very high (diagnostic DNA testing for all) to somewhat lower (e.g., MSI testing and then diagnostic testing). These strategies will also have varying specificities and costs associated with implementing the testing strategies. For this reason, we undertook a simple cost-consequences analysis with the primary outcome being the number of probands (newly diagnosed CRC cases) identified with Lynch syndrome. Once diagnosed, these probands with Lynch syndrome could then, theoretically, contact first-degree relatives who could consider targeted testing for the family mutation. Thus, the secondary outcome is the number of probands plus the number of relatives identified with Lynch syndrome. Lastly, the incremental costs associated with each of the strategies can be computed, using the one found to be least costly as the baseline.

The four strategies examined were selected because they demonstrated an important target (e.g., Strategy 1 has the highest possible sensitivity) or because they are used (or proposed to be used) in routine clinical practice. The four strategies formally compared are listed below with a short description. All assume that 150,000 individuals are approached and 100,000 agree to the first line of testing. After the first line of testing, uptake rates from the literature are used.

- Strategy 1: All newly diagnosed CRC cases (probands) are offered diagnostic testing (sequencing and deletion/large rearrangement analysis for $M S H 2, M L H 1$, and $M S H 6$ ). The order of MMR gene testing is selected because of both costs (MSH6 testing is most expensive) and prevalence (mutations in MSH6 are less common).

- Strategy 2: All newly diagnosed CRC cases are offered MSI testing using at least three mononucleotide repeats. Inclusion of three mononucleotide repeats may be an important component in improving the sensitivity of MSI testing, and assuming that most laboratories would be using the NCI standard of five markers (which already includes two mononucleotide repeats), the target of three could be met with a panel of six markers. Those with an MSI-high result are offered diagnostic testing of the three MMR genes in the same order as Strategy 1.

- Strategy 3: All newly diagnosed CRC cases are offered IHC testing (for all four MMR genes) and two thirds agree. Those with one or more absent stains are offered diagnostic testing for specific MMR genes, depending on which MMR proteins are absent.

- Strategy 4: The same as Strategy 3, except all individuals with absent MLH1 staining are then offered $B R A F$ muta- 
Table 14 Cost-consequence model describing the costs of identifying Lynch syndrome among a cohort of 150,000 newly diagnosed colorectal cancer (CRC) cases and among the relatives of probands with Lynch syndrome

\begin{tabular}{|c|c|c|c|c|c|c|c|c|}
\hline \multirow[b]{2}{*}{ Outcome measure } & \multicolumn{2}{|c|}{ Strategy $1^{a}$} & \multicolumn{2}{|c|}{ Strategy $2^{b}$} & \multicolumn{2}{|c|}{ Strategy $3^{c}$} & \multicolumn{2}{|c|}{ Strategy $4^{d}$} \\
\hline & Number & Costs & Number & Costs & Number & Costs & Number & Costs \\
\hline \multicolumn{9}{|l|}{ Considering only the probands } \\
\hline $\begin{array}{l}\text { Inform newly diagnosed } \\
\text { CRC cases }\end{array}$ & 150,000 & & 150,000 & 3.0 & 150,000 & 3.0 & 150,000 & 3.0 \\
\hline $\begin{array}{l}\text { CRC cases accepting } \\
\text { testing }\end{array}$ & 100,000 & & 100,000 & & 100,000 & & 100,000 & \\
\hline $\begin{array}{l}\text { Detectable Lynch syndrome } \\
\text { (LS) }\end{array}$ & 3000 & & 3000 & & 3000 & & 3000 & \\
\hline $\begin{array}{l}\text { MSI testing (six or more } \\
\text { markers) }\end{array}$ & ND & & 100,000 & 68.7 & ND & & ND & \\
\hline $\begin{array}{l}\text { IHC testing (all four MMR } \\
\text { genes) }\end{array}$ & ND & & ND & & 100,000 & 26.1 & 100,000 & 26.1 \\
\hline $\begin{array}{l}B R A F \text { V600E mutation } \\
\text { testing }\end{array}$ & ND & & ND & & ND & & 8775 & 0.5 \\
\hline Counseling probands & 150,000 & 26.1 & 12,060 & 2.1 & 13,354 & 2.3 & 6405 & 1.1 \\
\hline $\begin{array}{l}\text { DNA sequence/deletion test } \\
\text { of one gene }\end{array}$ & 296,609 & 252.3 & 43,195 & 28.0 & 17,576 & 12.3 & 11,262 & 7.8 \\
\hline Lynch syndrome detected & 2537 & & 2198 & & 2105 & & 2097 & \\
\hline $\begin{array}{l}\text { Lynch syndrome detection } \\
\text { rate }(\%)\end{array}$ & 84.6 & & 73.3 & & 70.2 & & 69.9 & \\
\hline False positive LS & 144 & & 16 & & 6 & & 4 & \\
\hline Counseling putative LS & 2681 & 0.3 & 2198 & 0.2 & 2111 & 0.2 & 2101 & 0.2 \\
\hline Total costs & & 279 & & 104 & & 45.9 & & 40.7 \\
\hline $\begin{array}{l}\text { Average cost per LS } \\
\text { detected }\end{array}$ & & $\$ 111,825$ & & $\$ 47,268$ & & $\$ 21,315$ & & $\$ 18,863$ \\
\hline $90 \%$ Confidence interval & $\$ 83,02$ & 48,040 & $\$ 33,26$ & $-64,241$ & $\$ 14,38$ & $-29,441$ & $\$ 12,94$ & $-26,111$ \\
\hline \multicolumn{9}{|l|}{ Considering the probands } \\
\hline Relatives approachable & 10,727 & 1.1 & 8856 & 0.9 & 8445 & 0.8 & 8406 & 0.8 \\
\hline $\begin{array}{l}\text { Relatives accepting } \\
\text { counseling }\end{array}$ & 5578 & 1.0 & 4605 & 0.8 & 4392 & 0.8 & 4371 & 0.8 \\
\hline $\begin{array}{l}\text { Relatives having targeted } \\
\text { testing }\end{array}$ & 5299 & 0.3 & 4375 & 0.2 & 4172 & 0.2 & 4152 & 0.2 \\
\hline $\begin{array}{l}\text { Relatives w/mutation } \\
\quad \text { (counseling) }\end{array}$ & 1504 & 0.1 & 1303 & 0.1 & 1248 & 0.1 & 1243 & 0.1 \\
\hline Additional costs & & 2 & & 2 & & 2 & & 2 \\
\hline \multicolumn{9}{|c|}{ Considering the probands and their relatives } \\
\hline Total LS detected & 4041 & & 3501 & & 3353 & & 3340 & \\
\hline $\begin{array}{l}\text { Average costs per LS } \\
\text { detected }\end{array}$ & & $\$ 71,869$ & & $\$ 30,705$ & & $\$ 14,163$ & & $\$ 12,600$ \\
\hline $90 \%$ Confidence interval & $\$ 49,17$ & 00,711 & $\$ 20,16$ & $-43,632$ & $\$ 9,18$ & $-20,359$ & $\$ 8,30$ & $-17,968$ \\
\hline Total program costs & $\$ 281$ & 0,000 & $\$ 104$, & 0,000 & $\$ 46$, & 0,000 & $\$ 41$, & 0,000 \\
\hline $\begin{array}{l}\text { Incremental costs per LS } \\
\text { detected }\end{array}$ & $\$ 348,000$ & $4 \mathrm{k}-\$ 504 \mathrm{k})$ & $\begin{array}{r}\$ 312,000 \\
\text { ti }\end{array}$ & $\begin{array}{l}2 \% \text { of the } \\
\text { e) }\end{array}$ & $\$ 398,000$ & 180-\$940k) & & rent \\
\hline
\end{tabular}


tion testing and only those without the V600E mutation continue for diagnostic testing. Those with present MLH1 staining (but absent staining for other MMR gene proteins) are treated as in Strategy 3.

- Table 13 shows the information used to inform the economic model; much of it drawn from the current evidence report. The modeling was performed using @RISK v4.5.7 (Palisade Corporation, Ithaca, NY), a Microsoft Excel add-in. All variables, except the 150,000 newly diagnosed cases and 100,000 agreeing to initial testing, were subjected to sensitivity analysis (often assuming a Gaussian distribution centered at the baseline value with a standard deviation equal to $20 \%$ of the baseline value). Costs per case of Lynch syndrome detected are provided with $90 \%$ confidence intervals based on probabilistic sensitivity analysis with convergence after 5000 iterations. A copy of the model suitable for use with @ RISK along with additional information about data used to inform the model (e.g., range of estimates, order of testing) are available from the authors.

- Table 14 shows the results of the cost-consequences analysis for the four example strategies using a population of 150,000 newly diagnosed CRC cases (the approximate number for 2007 in the United States). The rows under Strategy 1 shows the number (and, if appropriate, costs) associated with each activity derived using the baseline estimates. For example, among the 150,000 new CRC cases, 100,000 agree to be tested. Among those 100,000 cases, 3,000 individuals with MMR gene mutations (detectable Lynch syndrome) are estimated to be present. No preliminary laboratory tests are offered. All 150,000 cases need to be provided with information and counseling costing an estimated \$26.1 million. DNA sequencing of the 100,000 cases costs an additional $\$ 252$ million for the 296,609 sequencing tests performed (each cases needs to be sequenced for each of the three MMR genes, unless a mutation is found first). The total cost is then divided by the number of probands identified with Lynch syndrome to yield the cost per case detected. The reported $\$ 111,825$ is the average of the 5000 modeled costs per case detected used for sensitivity analysis and is slightly higher than the baseline estimate. The $90 \%$ confidence interval is provided as a measure of the overall reliability of that estimate. Similar analyses are performed for the relatives of probands identified with Lynch syndrome (bottom half of Table 14)

- The number of Lynch syndrome cases detected decreases from Strategies 1 through 4 (2537 of 3000 [85\%] to 2097 of $3000[69.9 \%])$. However, costs per proband diagnosed with Lynch syndrome, costs per proband and relatives diagnosed with Lynch syndrome, and total costs also decrease from Strategies 1 through 4 . For example, the cost per proband with CRC detected with Lynch syndrome drops from a high of $\$ 111,825$ with Strategy 1 to $\$ 18,863$ with Strategy 4 . The baseline total costs for the four strategies drop from $\$ 279$ million to $\$ 41$ million. Whether the tradeoff between lower detection (and lower costs) or higher detection (and higher costs) is worthwhile can be approached by considering the medical benefits and harms via a CEA. Such modeling, however, is beyond the scope of this report.

- One important cost advantage for IHC testing is that the current Medicare reimbursement of \$261 is much less than the corresponding reimbursement for MSI testing (\$457). We reran the simulation with the assumption that the two tests both cost $\$ 457$ and found that much of the apparent advantage of IHC testing is negated. For example, the cost per proband detected for Strategy 2 and Strategy 3 is reported in Table 14 to be $\$ 47,000$ vs. $\$ 21,000$, but with equal costs of $\$ 457$, the costs for the two strategies are much closer, at $\$ 47,000$ vs. $\$ 31,000$, respectively. This illustrates the care that is needed in interpreting economic analyses.

\section{ACKNOWLEDGMENTS}

Funding for this study was provided by the National Office of Public Health Genomics, Centers for Disease Control and Prevention, through a contract (200-2003-01396-0128) with McKing Consulting Corporation, Inc.

We thank the members of the Technical Evaluation Panel, including EGAPP Working Group members Celia I. Kaye, MD, University of Colorado at Denver and Health Sciences Center; Margaret Piper, PhD, MPH, Blue Cross/Blue Shield Association Technology Evaluation Center; James E. Haddow, MD, Women and Infants Hospital, The Warren Alpert School of Medicine at Brown University; Sue Richards, PhD, Oregon Health and Science University; and Linda A. Bradley, PhD, National Office of Public Health Genomics, CDC, who provided guidance and comments on drafts of this manuscript. We also thank Scott D. Grosse, PhD, National Center on Birth Defects and Developmental Disabilities, CDC and Mercy Mvundura, PhD, National Office of Public Health Genomics, $\mathrm{CDC}$, for their helpful comments regarding the economic analyses.

\section{REFERENCES}

1. Bonis PA, Trikalinos TA, Chung M, et al. Hereditary nonpolyposis colorectal cancer: accuracy of diagnostic strategies and implications to patients with colorectal cancer and their families. Evidence report/technology assessment No. 07-E008. Rockville, MD: Agency for Healthcare Research and Quality, 2007.

2. EGAPP Working Group. Recommendations from the EGAPP Working Group: Genetic testing strategies in newly diagnosed individuals with colorectal cancer aimed at reducing morbidity and mortality from Lynch syndrome in relatives. Genet Med 2009;11:35-41.

3. Jass JR. Hereditary non-polyposis colorectal cancer: the rise and fall of a confusing term. World J Gastroenterol 2006;12:4943-4950.

4. Lindor NM, Rabe K, Petersen GM, et al. Lower cancer incidence in Amsterdam-I criteria families without mismatch repair deficiency: familial colorectal cancer type X. JAMA 2005;293:1979-1985.

5. Terdiman JP. It is time to get serious about diagnosing Lynch syndrome (hereditary nonpolyposis colorectal cancer with defective DNA mismatch repair) in the general population. Gastroenterology 2005;129:741-744

6. Lynch HT, Lynch JF, Lynch PM. Toward a consensus in molecular diagnosis of hereditary nonpolyposis colorectal cancer (Lynch syndrome). J Natl Cancer Inst 2007;99:261-263

7. Boland CR, Thibodeau SN, Hamilton SR, et al. A National Cancer Institute Workshop on Microsatellite Instability for cancer detection and familial predisposition: development of international criteria for the determination of microsatellite instability in colorectal cancer. Cancer Res 1998;58: $5248-5257$.

8. Bacher JW, Flanagan LA, Smalley RL, et al. Development of a fluorescent multiplex assay for detection of MSI-High tumors. Dis Markers 2004;20: 237-250.

9. Buhard O, Suraweera N, Lectard A, Duval A, Hamelin R. Quasimonomorphic mononucleotide repeats for high-level microsatellite instability analysis. Dis Markers 2004;20:251-257.

10. Barnetson RA, Tenesa A, Farrington SM, et al. Identification and survival of carriers of mutations in DNA mismatch-repair genes in colon cancer. N Engl J Med 2006;354:2751-2763.

11. Hendriks Y, Franken P, Dierssen JW, et al. Conventional and tissue microarray immunohistochemical expression analysis of mismatch repair in hereditary colorectal tumors. Am J Pathol 2003;162:469-477.

12. Hendriks YM, Wagner A, Morreau H, et al. Cancer risk in hereditary nonpolyposis colorectal cancer due to MSH6 mutations: impact on counseling and surveillance. Gastroenterology 2004;127:17-25.

13. Hoedema R, Monroe $\mathrm{T}$, Bos $\mathrm{C}$, et al. Genetic testing for hereditary 
nonpolyposis colorectal cancer. Am Surg 2003:69:387-391; discussion 391-392.

14. Lee SC, Guo JY, Lim R, et al. Clinical and molecular characteristics of hereditary non-polyposis colorectal cancer families in Southeast Asia. Clin Genet 2005;68: 137-145.

15. Niessen $\mathrm{RC}$, Berends $\mathrm{MJ}, \mathrm{Wu} \mathrm{Y}$, et al. Identification of mismatch repair gene mutations in young patients with colorectal cancer and in patients with multiple tumours associated with hereditary non-polyposis colorectal cancer. Gut 2006;55: $1781-1788$.

16. Wolf B, Henglmueller S, Janschek E, et al. Spectrum of germ-line MLH1 and MSH2 mutations in Austrian patients with hereditary nonpolyposis colorectal cancer. Wien Klin Wochenschr 2005;117:269-277.

17. Plaschke J, Engel C, Kruger S, et al. Lower incidence of colorectal cancer and later age of disease onset in 27 families with pathogenic MSH6 germline mutations compared with families with MLH1 or MSH2 mutations: the German Hereditary Nonpolyposis Colorectal Cancer Consortium. $J$ Clin Oncol 2004;22:4486-4494

18. Plevova P, Krepelova A, Papezova M, et al. Immunohistochemical detection of the hMLH1 and hMSH2 proteins in hereditary non-polyposis colon cancer and sporadic colon cancer. Neoplasma 2004;51:275-284.

19. Southey MC, Jenkins MA, Mead L, et al. Use of molecular tumor characteristics to prioritize mismatch repair gene testing in early-onset colorectal cancer. J Clin Oncol 2005;23:6524-6532.

20. Spaepen M, Vankeirsbilck B, Van Opstal S, et al. Germline mutations of the hMLH1 and hMSH2 mismatch repair genes in Belgian hereditary nonpolyposis colon cancer (HNPCC) patients. Fam Cancer 2006;5:179189

21. Giuffre G, Muller A, Brodegger T, et al. Microsatellite analysis of hereditary nonpolyposis colorectal cancer-associated colorectal adenomas by laser-assisted microdissection: correlation with mismatch repair protein expression provides new insights in early steps of tumorigenesis. $J \mathrm{Mol}$ Diagn 2005;7:160-170.

22. Murphy KM, Zhang S, Geiger T, et al. Comparison of the microsatellite instability analysis system and the Bethesda panel for the determination of microsatellite instability in colorectal cancers. $J$ Mol Diagn 2006;8:305311

23. Umar A, Boland CR, Terdiman JP, et al. Revised Bethesda Guidelines for hereditary nonpolyposis colorectal cancer (Lynch syndrome) and microsatellite instability. J Natl Cancer Inst 2004;96:261-268.

24. Baudhuin LM, Burgart LJ, Leontovich O, Thibodeau SN. Use of microsatellite instability and immunohistochemistry testing for the identification of individuals at risk for Lynch syndrome. Fam Cancer 2005;4:255-265.

25. Muller A, Giuffre G, Edmonston TB, et al. Challenges and pitfalls in HNPCC screening by microsatellite analysis and immunohistochemistry. $J$ Mol Diagn 2004;6:308-315.

26. Trusky CL, Sepulveda AR, Hunt JL. Assessment of microsatellite instability in very small microdissected samples and in tumor samples that are contaminated with normal DNA. Diagn Mol Pathol 2006;15:63-69.

27. Drobinskaya I, Gabbert HE, Moeslein G, Mueller W. A new method for optimizing multiplex DNA microsatellite analysis in low quality archival specimens. Anticancer Res 2005;25:3251-3258.

28. Pastrello C, Baglioni S, Tibiletti MG, et al. Stability of BAT26 in tumours of hereditary nonpolyposis colorectal cancer patients with MSH2 intragenic deletion. Eur J Hum Genet 2006;14:63-68.

29. Gaff CL, Rogers MT, Frayling IM. Variability and inequity in testing of somatic tissue for hereditary cancer: a survey of UK clinical practice. Clin Genet 2006;70:312-319.

30. Lindor NM, Smalley R, Barker M, et al. Ascending the learning curveMSI testing experience of a six-laboratory consortium. Cancer Biomark 2006;2:5-9.

31. Meiser B. Psychological impact of genetic testing for cancer susceptibility: an update of the literature. Psychooncology 2005;14:1060-1074.

32. Jass JR. HNPCC and sporadic MSI-H colorectal cancer: a review of the morphological similarities and differences. Fam Cancer 2004;3:93-100.

33. Cunningham JM, Kim CY, Christensen ER, et al. The frequency of hereditary defective mismatch repair in a prospective series of unselected colorectal carcinomas. Am J Hum Genet 2001;69:780-790.

34. Pinol V, Castells A, Andreu M, et al. Accuracy of revised Bethesda guidelines, microsatellite instability, and immunohistochemistry for the identification of patients with hereditary nonpolyposis colorectal cancer. JAMA 2005;293:1986-1994.

35. Salovaara R, Loukola A, Kristo P, et al. Population-based molecular detection of hereditary nonpolyposis colorectal cancer. J Clin Oncol 2000; 18:2193-2200

36. Hendriks YM, Jagmohan-Changur S, van der Klift HM, et al. Heterozygous mutations in PMS2 cause hereditary nonpolyposis colorectal carcinoma (Lynch syndrome). Gastroenterology 2006;130:312-322.

37. Hampel H, Frankel WL, Martin E, et al. Screening for the Lynch syndrome (hereditary nonpolyposis colorectal cancer). N Engl J Med 2005;352:18511860.

38. Aaltonen LA, Salovaara R, Kristo P, et al. Incidence of hereditary nonpol- yposis colorectal cancer and the feasibility of molecular screening for the disease. N Engl J Med 1998;338:1481-1487.

39. Cunningham JM, Christensen ER, Tester DJ, et al. Hypermethylation of the hMLH1 promoter in colon cancer with microsatellite instability. Cancer Res 1998;58:3455-3460.

40. Deng G, Peng E, Gum J, Terdiman J, Sleisenger M, Kim YS. Methylation of hMLH1 promoter correlates with the gene silencing with a regionspecific manner in colorectal cancer. Br J Cancer 2002;86:574-579.

41. Kane MF, Loda M, Gaida GM, et al. Methylation of the hMLH1 promoter correlates with lack of expression of hMLH1 in sporadic colon tumors and mismatch repair-defective human tumor cell lines. Cancer Res 1997;57: $808-811$

42. Kuismanen SA, Holmberg MT, Salovaara R, de la Chapelle A, Peltomaki $\mathrm{P}$. Genetic and epigenetic modification of MLH1 accounts for a major share of microsatellite-unstable colorectal cancers. Am J Pathol 2000;156:17731779

43. Menigatti M, Di Gregorio C, Borghi F, et al. Methylation pattern of different regions of the MLH1 promoter and silencing of gene expression in hereditary and sporadic colorectal cancer. Genes Chromosomes Cancer 2001;31:357-361

44. Zeps N, Iacopetta BJ, Schofield L, George JM, Goldblatt J. Waiver of individual patient consent in research: when do potential benefits to the community outweigh private rights? Med J Aust 2007;186:88-90.

45. Lakhani SR, Van De Vijver MJ, Jacquemier J, et al. The pathology of familial breast cancer: predictive value of immunohistochemical markers estrogen receptor, progesterone receptor, HER-2, and p53 in patients with mutations in BRCA1 and BRCA2. J Clin Oncol 2002;20:2310-2318.

46. Popat S, Hubner R, Houlston RS. Systematic review of microsatellite instability and colorectal cancer prognosis. J Clin Oncol 2005;23:609-618.

47. Kim GP, Colangelo LH, Wieand HS, et al. Prognostic and predictive roles of high-degree microsatellite instability in colon cancer: a National Cancer Institute-National Surgical Adjuvant Breast and Bowel Project Collaborative Study. J Clin Oncol 2007;25:767-772.

48. Vasen HF, Moslein G, Alonso A, et al. Guidelines for the clinical management of Lynch syndrome (hereditary non-polyposis cancer). J Med Genet 2007;44:353-362.

49. Lindor NM, Petersen GM, Hadley DW, et al. Recommendations for the care of individuals with an inherited predisposition to Lynch syndrome: a systematic review. JAMA 2006;296:1507-1517.

50. Guillem JG, Wood WC, Moley JF, et al. ASCO/SSO review of current role of risk-reducing surgery in common hereditary cancer syndromes. $J$ Clin Oncol 2006;24:4642-4660.

51. de Vos tot Nederveen Cappel WH, Buskens E, van Duijvendijk P, et al. Decision analysis in the surgical treatment of colorectal cancer due to a mismatch repair gene defect. Gut 2003;52:1752-1755.

52. Fallik D, Borrini F, Boige V, et al. Microsatellite instability is a predictive factor of the tumor response to irinotecan in patients with advanced colorectal cancer. Cancer Res 2003;63:5738-5744.

53. Jacob S, Aguado M, Fallik D, Praz F. The role of the DNA mismatch repair system in the cytotoxicity of the topoisomerase inhibitors camptothecin and etoposide to human colorectal cancer cells. Cancer Res 2001;61:65556562.

54. Aktan-Collan K, Mecklin JP, Jarvinen H, et al. Predictive genetic testing for hereditary non-polyposis colorectal cancer: uptake and long-term satisfaction. Int $J$ Cancer 2000;89:44-50.

55. Rowley PT. Screening for an inherited susceptibility to colorectal cancer Genet Test 2004;8:421-430

56. Arver B, Haegermark A, Platten U, Lindblom A, Brandberg Y. Evaluation of psychosocial effects of pre-symptomatic testing for breast/ovarian and colon cancer pre-disposing genes: a 12-month follow-up. Fam Cancer 2004;3:109-116

57. Keller M, Jost R, Kadmon M, et al. Acceptance of and attitude toward genetic testing for hereditary nonpolyposis colorectal cancer: a comparison of participants and nonparticipants in genetic counseling. Dis Colon Rectum 2004;47:153-162.

58. Quehenberger F, Vasen HF, van Houwelingen HC. Risk of colorectal and endometrial cancer for carriers of mutations of the hMLH1 and hMSH2 gene: correction for ascertainment. J Med Genet 2005;42:491-496.

59. Jenkins MA, Baglietto L, Dowty JG, et al. Cancer risks for mismatch repair gene mutation carriers: a population-based early onset case-family study. Clin Gastroenterol Hepatol 2006;4:489-498.

60. Mitchell RJ, Farrington SM, Dunlop MG, Campbell H. Mismatch repair genes hMLH1 and hMSH2 and colorectal cancer: a HuGE review. Am J Epidemiol 2002;156:885-902.

61. Buttin BM, Powell MA, Mutch DG, et al. Penetrance and expressivity of MSH6 germline mutations in seven kindreds not ascertained by family history. Am J Hum Genet 2004;74:1262-1269.

62. Wagner A, Hendriks Y, Meijers-Heijboer EJ, et al. Atypical HNPCC owing to MSH6 germline mutations: analysis of a large Dutch pedigree. $J$ Med Genet 2001;38:318-322.

63. Vasen HF, Stormorken A, Menko FH, et al. MSH2 mutation carriers are at 
higher risk of cancer than MLH1 mutation carriers: a study of hereditary nonpolyposis colorectal cancer families. J Clin Oncol 2001;19:4074-4080.

64. Aarnio M, Sankila R, Pukkala E, et al. Cancer risk in mutation carriers of DNA-mismatch-repair genes. Int J Cancer 1999;81:214-218.

65. Hampel H, Stephens JA, Pukkala E, et al. Cancer risk in hereditary nonpolyposis colorectal cancer syndrome: later age of onset. Gastroenterology 2005;129:415-421.

66. Vasen HF, Wijnen JT, Menko FH, et al. Cancer risk in families with hereditary nonpolyposis colorectal cancer diagnosed by mutation analysis. Gastroenterology 1996;110:1020-1027.

67. Alarcon F, Lasset C, Carayol J, et al. Estimating cancer risk in HNPCC by the GRL method. Eur J Hum Genet 2007;15:831-836.

68. Beery TA, Williams JK. Risk reduction and health promotion behaviors following genetic testing for adult-onset disorders. Genet Test 2007;11: 111-123.

69. Claes E, Denayer L, Evers-Kiebooms G, et al. Predictive testing for hereditary nonpolyposis colorectal cancer: subjective perception regarding colorectal and endometrial cancer, distress, and health-related behavior at one year post-test. Genet Test 2005;9:54-65

70. Collins V, Meiser B, Gaff C, St John DJ, Halliday J. Screening and preventive behaviors one year after predictive genetic testing for hereditary nonpolyposis colorectal carcinoma. Cancer 2005;104:273-281.

71. Halbert $\mathrm{CH}$, Lynch $\mathrm{H}$, Lynch J, et al. Colon cancer screening practices following genetic testing for hereditary nonpolyposis colon cancer (HNPCC) mutations. Arch Intern Med 2004;164:1881-1887.

72. Johnson KA, Trimbath JD, Petersen GM, Griffin CA, Giardiello FM. Impact of genetic counseling and testing on colorectal cancer screening behavior. Genet Test 2002;6:303-306.

73. Loader S, Shields C, Rowley PT. Impact of genetic counseling and DNA testing on individuals with colorectal cancer with a positive family history: a population-based study. Genet Test 2005;9:313-319.

74. Ponz de Leon M, Benatti P, Di Gregorio C, et al. Genetic testing among high-risk individuals in families with hereditary nonpolyposis colorectal cancer. Br J Cancer 2004;90:882-887.

75. Wagner A, van Kessel I, Kriege MG, et al. Long term follow-up of HNPCC gene mutation carriers: compliance with screening and satisfaction with counseling and screening procedures. Fam Cancer 2005;4:295-300.

76. Hadley DW, Jenkins JF, Dimond E, et al. Colon cancer screening practices after genetic counseling and testing for hereditary nonpolyposis colorectal cancer. J Clin Oncol 2004;22:39-44.

77. Smith RA, von Eschenbach AC, Wender R, et al. American Cancer Society guidelines for the early detection of cancer: update of early detection guidelines for prostate, colorectal, and endometrial cancers. Also: update 2001-testing for early lung cancer detection. CA Cancer J Clin 2001;51: $38-75$; quiz $77-80$

78. Winawer S, Fletcher R, Rex D, et al. Colorectal cancer screening and surveillance: clinical guidelines and rationale-Update based on new evidence. Gastroenterology 2003;124:544-560.

79. Tan JJ, Tjandra JJ. Which is the optimal bowel preparation for colonoscopy - a meta-analysis. Colorectal Dis 2006;8:247-258.

80. Barkun A, Chiba N, Enns R, et al. Commonly used preparations for colonoscopy: efficacy, tolerability, and safety - a Canadian Association of Gastroenterology position paper. Can J Gastroenterol 2006;20:699-710.

81. Cobb WS, Heniford BT, Sigmon LB, et al. Colonoscopic perforations: incidence, management, and outcomes. Am Surg 2004;70:750-757; discussion 757-758.

82. Gatto NM, Frucht H, Sundararajan V, Jacobson JS, Grann VR, Neugut AI. Risk of perforation after colonoscopy and sigmoidoscopy: a populationbased study. J Natl Cancer Inst 2003;95:230-236.

83. Levin TR, Zhao W, Conell C, et al. Complications of colonoscopy in an integrated health care delivery system. Ann Intern Med 2006;145:880-886.

84. Rathgaber SW, Wick TM. Colonoscopy completion and complication rates in a community gastroenterology practice. Gastrointest Endosc 2006;64: $556-562$.

85. Korman LY, Overholt BF, Box T, Winker CK. Perforation during colonoscopy in endoscopic ambulatory surgical centers. Gastrointest Endosc 2003; 58:554-557.

86. Viiala CH, Zimmerman M, Cullen DJ, Hoffman NE. Complication rates of colonoscopy in an Australian teaching hospital environment. Intern Med J 2003;33:355-359.

87. Nelson DB, McQuaid KR, Bond JH, Lieberman DA, Weiss DG, Johnston TK. Procedural success and complications of large-scale screening colonoscopy. Gastrointest Endosc 2002;55:307-314.

88. Dafnis G, Ekbom A, Pahlman L, Blomqvist P. Complications of diagnostic and therapeutic colonoscopy within a defined population in Sweden. Gastrointest Endosc 2001;54:302-309.

89. Anderson ML, Pasha TM, Leighton JA. Endoscopic perforation of the colon: lessons from a 10-year study. Am J Gastroenterol 2000;95:34183422 .

90. Zubarik R, Fleischer DE, Mastropietro C, et al. Prospective analysis of complications 30 days after outpatient colonoscopy. Gastrointest Endosc 1999;50:322-328.

91. Eckardt VF, Kanzler G, Schmitt T, Eckardt AJ, Bernhard G. Complications and adverse effects of colonoscopy with selective sedation. Gastrointest Endosc 1999;49:560-565

92. Waye JD, Kahn O, Auerbach ME. Complications of colonoscopy and flexible sigmoidoscopy. Gastrointest Endosc Clin N Am 1996;6:343-377.

93. Jarvinen HJ, Aarnio M, Mustonen H, et al. Controlled 15-year trial on screening for colorectal cancer in families with hereditary nonpolyposis colorectal cancer. Gastroenterology 2000;118:829-834.

94. de Jong AE, Hendriks YM, Kleibeuker JH, et al. Decrease in mortality in Lynch syndrome families because of surveillance. Gastroenterology 2006; 130:665-671

95. Elton C, Makin G, Hitos K, Cohen CR. Mortality, morbidity and functional outcome after ileorectal anastomosis. Br J Surg 2003;90:59-65.

96. Van Duijvendijk P, Slors JF, Taat CW, et al. Quality of life after total colectomy with ileorectal anastomosis or proctocolectomy and ileal pouchanal anastomosis for familial adenomatous polyposis. Br J Surg 2000;87: $590-596$.

97. American College of Obstetricians and Gynecologists. ACOG practice bulletin, clinical management guidelines for obstetrician-gynecologists, number 65, August 2005: management of endometrial cancer. Obstet Gynecol 2005; 106:413-425.

98. Dove-Edwin I, Boks D, Goff S, et al. The outcome of endometrial carcinoma surveillance by ultrasound scan in women at risk of hereditary nonpolyposis colorectal carcinoma and familial colorectal carcinoma. Cancer 2002;94:1708-1712

99. Renkonen-Sinisalo L, Butzow R, Leminen A, Lehtovirta P, Mecklin JP, Järvinen HJ. Surveillance for endometrial cancer in hereditary nonpolyposis colorectal cancer syndrome. Int J Cancer 2007;120:821-824.

100. Rijcken FE, Mourits MJ, Kleibeuker JH, Hollema Hvan der Zee AG. Gynecologic screening in hereditary nonpolyposis colorectal cancer. $G y$ necol Oncol 2003;91: 74-80.

101. Vuento MH, Maatela JI, Tyrkko JE, Laippala PJ, Grönroos M, Salmi TA. A longitudinal study of screening for endometrial cancer by endometrial biopsy in diabetic females. Int J Gynecol Cancer 1995;5:390-395.

102. Lecuru F, Metzger U, Scarabin C, Le Frère Belda MA, Olschwang S, Laurent Puig P. Hysteroscopic findings in women at risk of HNPCC. Results of a prospective observational study. Fam Cancer 2007;6:295-299.

103. Schmeler KM, Lynch HT, Chen LM, et al. Prophylactic surgery to reduce the risk of gynecologic cancers in the Lynch syndrome. $N$ Engl $\mathrm{J} \mathrm{Med}$ 2006;354:261-269.

104. Garry R, Fountain J, Mason S, et al. The eVALuate study: two parallel randomised trials, one comparing laparoscopic with abdominal hysterectomy, the other comparing laparoscopic with vaginal hysterectomy. BMJ 2004;328:129.

105. Makinen J, Johansson J, Tomas C, et al. Morbidity of 10110 hysterectomies by type of approach. Hum Reprod 2001;16:1473-1478.

106. Meltomaa SS, Makinen JI, Taalikka MO, Helenius HY. One-year cohort of abdominal, vaginal, and laparoscopic hysterectomies: complications and subjective outcomes. J Am Coll Surg 1999;189:389-396.

107. Olsson JH, Ellstrom M, Hahlin M. A randomised prospective trial comparing laparoscopic and abdominal hysterectomy. Br J Obstet Gynaecol 1996; $103: 345-350$

108. Johnson N, Barlow D, Lethaby A, Tavender E, Curr L, Garry R. Methods of hysterectomy: systematic review and meta-analysis of randomised controlled trials. BMJ 2005;330:1478.

109. Domchek SM, Rebbeck TR. Prophylactic oophorectomy in women at increased cancer risk. Curr Opin Obstet Gynecol 2007;19:27-30.

110. Shoupe D, Parker WH, Broder MS, Liu Z, Farquhar C, Berek JS. Elective oophorectomy for benign gynecological disorders. Menopause 2007; 14: $580-585$

111. Watson P, Vasen HF, Mecklin JP, et al. The risk of extra-colonic, extraendometrial cancer in the Lynch syndrome. Int J Cancer 2008;123:444449.

112. Myrhoj T, Andersen MB, Bernstein I. Screening for urinary tract cancer with urine cytology in Lynch syndrome and familial colorectal cancer. Fam Cancer 2008;7:303-307.

113. Collins VR, Meiser B, Ukoumunne OC, Gaff C, St John DJ, Halliday JL. The impact of predictive genetic testing for hereditary nonpolyposis colorectal cancer: three years after testing. Genet Med 2007;9:290-297.

114. Meiser B, Collins V, Warren R, et al. Psychological impact of genetic testing for hereditary non-polyposis colorectal cancer. Clin Genet 2004;66: $502-511$

115. Aktan-Collan K, Haukkala A, Mecklin JP, Uutela AKaariainen H. Comprehension of cancer risk one and 12 months after predictive genetic testing for hereditary non-polyposis colorectal cancer. J Med Genet 2001;38:787792

116. Gritz ER, Peterson SK, Vernon SW, et al. Psychological impact of genetic testing for hereditary nonpolyposis colorectal cancer. J Clin Oncol 2005; 23:1902-1910. 
117. Trimbath JD, Giardiello FM. Review article: genetic testing and counselling for hereditary colorectal cancer. Aliment Pharmacol Ther 2002;16: 1843-1857.

118. Breheny N, Geelhoed E, Goldblatt J, Ee H, O'Leary P. Economic evaluation of the familial cancer programme in Western Australia: predictive genetic testing for familial adenomatous polyposis and hereditary nonpolyposis colorectal carcinoma. Community Genet 2006;9:9-106.

119. Olsen KR, Bojesen SE, Gerdes AM, Lindorff-Larsen K, Bernstein IT. Cost-effectiveness of surveillance programs for families at high and moderate risk of hereditary non-polyposis colorectal cancer. Int J Technol Assess Health Care 2007;23:89-95.

120. Syngal S, Weeks JC, Schrag D, Garber JE, Kuntz KM. Benefits of colonoscopic surveillance and prophylactic colectomy in patients with hereditary nonpolyposis colorectal cancer mutations. Ann Intern Med 1998;129:787796.

121. Vasen HF, van Ballegooijen M, Buskens E, et al. A cost-effectiveness analysis of colorectal screening of hereditary nonpolyposis colorectal carcinoma gene carriers. Cancer 1998;82:1632-1637.

122. Luo DC, Cai Q, Sun MH, et al. Clinicopathological and molecular genetic analysis of HNPCC in China. World J Gastroenterol 2005;11:1673-1679.

123. Overbeek LIH, Kets CM, Hebeda KM, et al. Patients with an unexplained microsatellite instable tumour have a low risk of familial cancer. $\mathrm{Br} J$ Cancer 2007;96:1605-1612.

124. Wang L, Cunningham JM, Winters JL, et al. BRAF mutations in colon cancer are not likely attributable to defective DNA mismatch repair. Cancer Res 2003;63:5209-5212.
125. Loughrey MB, Waring PM, Tan A, et al. Incorporation of somatic BRAF mutation testing into an algorithm for the investigation of hereditary non-polyposis colorectal cancer. Fam Cancer 2007;6:301-310.

126. Kambara T, Simms LA, Whitehall VL, et al. BRAF mutation is associated with DNA methylation in serrated polyps and cancers of the colorectum. Gut 2004;53:1137-1144.

127. Aktan-Collan K, Haukkala A, Pylvanainen K, et al. Direct contact in inviting high-risk members of hereditary colon cancer families to genetic counselling and DNA-testing. J Med Genet 2007;44:732-738.

128. Hadley DW, Jenkins J, Dimond E, et al. Genetic counseling and testing in families with hereditary nonpolyposis colorectal cancer. Arch Intern Med 2003;163:573-582

129. Stanley AJ, Gaff CL, Aittomaki AK, Fabre LC, Macrae FA, St John J. Value of predictive genetic testing in management of hereditary nonpolyposis colorectal cancer (HNPCC). Med J Aust 2000;172:313-316.

130. Lerman C, Hughes C, Trock BJ, et al. Genetic testing in families with hereditary nonpolyposis colon cancer. JAMA 1999;281:1618-1622.

131. Codori AM, Petersen GM, Miglioretti DL, et al. Attitudes toward colon cancer gene testing: factors predicting test uptake. Cancer Epidemiol Biomarkers Prev 1999;8:345-351.

132. Dunlop MG, Farrington SM, Carothers AD, et al. Cancer risk associated with germline DNA mismatch repair gene mutations. Hum Mol Genet 1997;6:105-110.

133. Ramsey SD, Burke W, Clarke L. An economic viewpoint on alternative strategies for identifying persons with hereditary nonpolyposis colorectal cancer. Genet Med 2003;5:353-363. 